Research Article

\title{
Collaborative Innovation with Dynamic Incentive Contracts in a Supply Chain
}

\author{
Yifei Hao, ${ }^{1,2}$ Wei Chen $\mathbb{D}^{2,3}$ and Hong Yang ${ }^{4}$ \\ ${ }^{1}$ College of Mathematics and Statistics, Chongqing Technology and Business University, Chongqing 400067, China \\ ${ }^{2}$ Research Center for Enterprise Management, Chongqing Technology and Business University, Chongqing 400067, China \\ ${ }^{3}$ School of Management, Chongqing Technology and Business University, Chongqing 400067, China \\ ${ }^{4}$ School of Geography and Tourism, Chongqing Normal University, Chongqing 400047, China \\ Correspondence should be addressed to Wei Chen; chenwei@ctbu.edu.cn
}

Received 1 December 2019; Revised 15 February 2020; Accepted 19 March 2020; Published 25 April 2020

Academic Editor: Jean Jacques Loiseau

Copyright $\odot 2020$ Yifei Hao et al. This is an open access article distributed under the Creative Commons Attribution License, which permits unrestricted use, distribution, and reproduction in any medium, provided the original work is properly cited.

\begin{abstract}
The collection and sharing of consumers' knowledge by retailers can help manufacturers improve the innovation level of products, thereby improving the performance of supply chain. However, due to the cost of collecting consumers' knowledge, the wholesale price contract can no longer coordinate supply chain members effectively. It is necessary to study the problem how the retailers are encouraged to make more efforts for the cooperative innovation with manufacturers. This paper introduces two dynamic incentive contracts for improving collaborative innovation level in a two-player supply chain, and the impacts of these contracts on supply chain's performance are investigated, by using a Stackelberg differential game model. The manufacturer, as a Stackelberg leader, determines the R\&D investment while the retailer is responsible for the retail price and the efforts in collection of the consumer's information (or preference) to the products. The model incorporates a wholesale price contract and two incentive contracts to better understand how the manufacturer can facilitate the retailer's efforts in the collection of consumer's information and increase the profits of the members of supply chain. Our results suggest that the optimal profit of the supply chain, the retailer's efforts in the collection of consumer's knowledge, the retail price, and the innovation level under the reward incentive contract are higher than their counterparts in other contracts. In particular, the retailer's optimal effort under the reward incentive contract is even higher than the one in the centralized decision scenario. However, if the manufacturer commits an effort target to the retailer, it shows that the retailer's optimal effort is independent of the target. The manufacturer's optimal R\&D investments are constants in the three contracts under the dynamic setting. Furthermore, numerical simulations show that the effort target has little impact on profits of the supply chain although it affects the decision making of supply chain members to some extent, whereas the retailer's marginal reward offered by the manufacturer influences the innovation level of product and the supply chain's profit significantly.
\end{abstract}

\section{Introduction}

Product innovation has an impact on consumers' demand, and retailers' collection and sharing of consumers' knowledge (or preference) can help manufacturers improve the level of product innovation. However, retailers always do not provide the best collection efforts for their own interests, so manufacturers need to consider how to encourage retailers to increase their efforts. In addition, the product innovation is a dynamic process in the business environment nowadays, which also makes the problems in $\mathrm{R} \& \mathrm{D}$ coordination of supply chain more complex; hence, it is necessary to study the long-term incentive contracts of cooperative innovation in the supply chain. The cooperation of Procter \& Gamble Company (P\&G) with Walmart, Inc., is one of the most representative examples. In the early days, the two companies had little cooperation. They focused on the control of commodities' prices and the sales promotion, respectively, but shared little information and knowledge with each other. The benefits of collabration at the supply chain's level were soon recognized by the companies. Walmart begun to share consumer's information (e.g., membership card 
information) and preferences with $P \& G$ timely,as well as participated in P\&G's product design. Hence, $P \& G$ could launch new products that meet consumer's needs more quickly and precisely. On the other hand, in the 1960s, JVC and SONY invested in the development of VCR as a new business, but they could not grasp the potential consumer's demand in advance, so they had to constantly launch new products to the market for testing; it was very costly, until they successfully developed products in the 1970s after roughly understanding the consumer's demand for this new product.

Another motivation of this study is the development of the "New Retail" in China. New Retail is about bridging e-commerce, physical retail, and logistics in order to improve the efficiency of selling and buying, as well as improve the shopping experience. Consumer's preference for novel shopping experiences plays a critical role in this new business model, and the most forward-thinking brands also see them in the role of coproducers. As New Retail takes root, the brands that thrive will acknowledge that the changes they make today-the new capabilities they develop and the operating models they devise-won't necessarily help them in the next year. New Retail is a dynamic process, requiring brands to constantly refine and reinvent themselves for new occasions, new formats, and the steady flow of new ideas that will define retailing tomorrow. Pioneering supply chains also take an interactive approach to R\&D that allows for timely changes in design and planning based on real-time consumer's preference and behavior. The supply chain becomes more complex when a manufacturer integrates consumer's knowledge into R\&D and production; he needs accurate consumer's knowledge and preference toward the product, while the retailer has the advantages to obtain these information. Hence, the supply chain dynamic coordination becomes more important since the appearance of the New Retail. It motivates us to explore the efficient coordination methods to stimulate the retailer to make effort to grasp the consumer's need precisely and then improve the competitiveness of the supply chain.

The above examples and many previous research studies [1-3] show that deep collaboration and knowledge sharing among supply chain members may help each enterprise achieve higher return rates. In order to meet consumer's demand for product performance and improve market competitiveness, the manufacturer usually invests in $R \& D$ to improve innovation level of his product. Meanwhile, the retailer can make efforts to collect the consumer's knowledge about the products. Specifically, the retailer can provide the information about consumer's preferences and other market demands, so as to assist the manufacturer to improve the innovation level of the product and meet consumer's needs precisely. Since both manufacturer's R\&D investment and retailer's effort in the collection of consumer's knowledge can improve innovation level and the profit of the enterprises will be increased, the supply chain's market competitiveness can also be improved, and they are motivated to cooperate in $\mathrm{R} \& \mathrm{D}$ to improve innovation level in the long term. However, the traditional wholesale price contract may not be enough to encourage the retailer to make efforts in the collection of consumer's knowledge, which may affect the innovation level improvement and subsequently affect the market demand, so it may not facilitate the long-term coordination of the supply chain. Therefore, we present two incentive contracts to coordinate the supply chain and compare them with the wholesale price contract. The results show that the incentive contracts indeed enhance the stimulation of the retailer's effort and improve the performance of the supply chain.

Notice that the innovation process is long period and dynamic, and the innovation level of product and firm's prior decision can affect the market demand of the next period. Therefore, the dynamics of the innovation problem should be taken into consideration [4]. In this paper, we study the innovation dynamics by using the dynamical programming theory and differential game theory. The manufacturer determines the $\mathrm{R} \& \mathrm{D}$ investment while the retailer is responsible for the effort in the collection of consumer's knowledge and the retail price to maximize their profits in the long period, respectively. Specifically, the manufacturer's R\&D investment affects the innovation level and subsequently increases the market demand; hence, the profit will be increased. The manufacturer would invest more in $R \& D$ until reaching the steady state. On the other hand, the retailer determines the retail price, and then she will see the market response of the price; subsequently, she decides the price of the next period according to the market demand. Therefore, this study investigates the coordinating innovation under the dynamic situation instead of the static one. We suppose the manufacturer and the retailer are farsighted: they seek to maximize their profits over the long term and consider the impact of innovation levels on the market demand (since the time lag exists, the innovation level is influenced by R\&D investment and effort in the collection of consumer's knowledge during the prior period).

Inspired by some previous literatures, e.g., [1, 3, 5-7], this paper investigates the cooperative innovation mechanisms of a supply chain which is composed of one manufacturer and one retailer under three transfer payment contracts: the wholesale price contract, the incentive contract based on the effort in consumer's knowledge collection, and the incentive contract based on the target effort in consumer's knowledge collection. The comparative analyses of the incentive contracts are derived. Although there are incentive mechanisms in some supply chains. For example, Suofeiya Home Collection Co., a Chinese customized furniture manufacturer, has implemented equity incentive policies for retailers in 2018. The policy has stimulated the retailers to make more efforts, such as obtaining the knowledge including consumers' personalized needs and preferences, independent design, services, marketing, and so on, to share with the manufacturer and help it to develop new products and innovate service and marketing methods. However, in this incentive process, the manufacturer deeply binds its own interests with retailers' interests. Our model proposes an alternative incentive mechanism which gives retailers greater autonomy. The manufacturer increases $\mathrm{R} \& \mathrm{D}$ investment and improves product innovation level, so 
as to increase sales revenue. The retailer participates in innovation through contract incentives and generates revenue expectation, so as to make more efforts to have more customers, mining customer knowledge and sharing this knowledge with manufacturer. The retailer cooperates with manufacturers to innovate in products, services, or marketing and finally improves the performance of supply chain. $\mathrm{We}$ intend to address the following questions from the perspective of maintaining long-term cooperative relations among supply chain members:

(1) What are the optimal equilibrium strategies of the supply chain membersin the different contracts?

(2) What are the differences between the two incentive contracts based on knowledge sharing? Which one is preferable to the supply chain's members?

(3) How will parameters in the contracts affect the decisions and profits of the supply chain's members?

By answering the above questions, we aim to contribute to the literature by bridging the gap between practice and academia. We will clarify the important implications for supply chain practices by offering practical guidelines to supply chain managers, including how to better facilitate the innovation level of the product and enhance the overall performance of a supply chain.

The main contributions of this paper are mainly reflected in the following aspects. (i) The product's innovation level, instead of the product's quality [8], is set to be the state variable. The consumers' personalized demand is increasing, and they are more sensitive to the innovation level of product, which directly affects the market demand for products. In addition, the innovation level is affected by the manufacturer's R\&D investment and the retailer's collection of consumer's knowledge. (ii) The product innovation is a dynamic process in the business environment nowadays; hence, it is necessary to study the long-term contracts of cooperative innovation in the supply chain. Moreover, we consider the dynamic incentive contracts between the supply chain members, whereas the previous studies mainly considered the static ones $[9,10]$. Both the manufacturer and retailer are farsighted; they consider the impact of the next period when they are making current decisions; this behavior makes the decision-making process to be continuous and iterative. (iii) As mentioned before, some manufacturers have realized the retailer's effort in collection of consumer's knowledge which can improve the innovation level of their product. It is necessary to explore the incentive mechanisms in the supply chains under the dynamic setting. Yoo and Cheong [7] introduced the incentive contracts for collaborative product quality improvement in static setting. Two incentive dynamic contracts are introduced in this study, and the results show that they are more efficient than the traditional wholesale price contract, and there are some novel managerial insights from the incentive dynamic contracts. In addition, the study of dynamic contracts can characterize the longterm decision problems appropriately in the collaborative innovation coordination of a supply chain.
The remainder of the paper is organized as follows. Section 2 discusses the related literature. Section 3 presents the assumptions and the notations used to address the problems in this paper. In Section 4, based on centralized decision and three kinds of contracts, four differential game models are formulated. Section 5 conducts a comparison between different contracts. Section 6 makes simulations and sensitivity analysis, and Section 7 concludes the paper.

\section{Literature Review}

This paper focuses mainly on three areas: the contract design and coordination of the supply chain; R\&D coordination of a supply chain; and the differential game model and its application in the supply chain management. Thus, we review studies relevant to each stream and highlight the differences between the current study and the existing literature.

2.1. Contract Design and Coordination of a Supply Chain. Since the contracts can motivate all the members of a supply chain, they are effective instruments to coordinate the supply chain. To improve the innovation level of the products, an effective way for the manufacturer is to establish a contract with the retailer. It is well known that if the contracts work cooperatively, it leads to the development of the potential competition in a supply chain. Thus, the researchers investigate different types of contract mechanisms to better understand the supply chain coordination. For example, Chen and Chen [1] found that the formal contract cannot motivate supply chain member's knowledge investment effectively. Under all discount rates, the degree of knowledge investment and participant income of cooperative innovation under relational contract are no less than that under formal contract. Hong and Guo [11] designed a contract to help the manufacturer achieve more profits considering environmental responsibilities. An improved revenuesharing contract was designed by Xu et al. [12] to effectively coordinate the manufacturer and retailer. Peng et al. [10] found that the quantity discount contracts can coordinate the low-carbon supply chain efficiently, rather than the revenue-sharing contract. A practical and new contract was designed by Alamdar et al. [13] to coordinate the decentralized closed-loop supply chain. Song and He [14] found that the decentralized supply chain can be coordinated by a freshness-keeping, cost-sharing, and revenue-sharing contract. Sun et al. [15] designed and analyzed the carbon emission reduction cost-sharing and carbon sink costsharing contracts, respectively. Several incentive mechanisms were investigated by Yoo and Cheong [7] for collaborative product quality improvement in a buyer-driven supply chain, and the impacts of those mechanisms on supply chain performance are studied. Li et al. [9] derived Bayesian-Nash equilibria for contract choice and found that a two-part tariff contract is superior to a wholesale price contract. Zou et al. [16] explored the optimal decision making on wholesale prices, retail prices, and recycling prices in a closed-loop supply chain under centralized and decentralized decision-making scenarios, respectively. Zhao 
et al. [17] examined optimal pricing in a two-tier product and service supply chain consisting of a manufacturer and a retailer in the context of vertical competition in extended warranty in two cases: one considering the retailer fairness concerns and one without considering the retailer fairness concerns. Zhou et al. [18] studied the dynamic incentive of supply chain under information asymmetry for the information screening in long-term supply chain cooperation. Noori-Daryan et al. [19] analyzed optimal pricing and replenishment decisions of a single-manufacturer/multipleretailer supply chain where a composite contract combines quantity and freight discounts. Taleizadeh et al. [20] developed a pricing-inventory model for a single-item twoechelon supply chain which was coordinated by three different incentive contracts.

2.2. R๘D Management and Coordination of a Supply Chain. $\mathrm{R} \& \mathrm{D}$ coordination among the members in a supply chain is receiving more and more attention in the fields of operations research and management, considering the revenue or cost sharing, consumer's preference, or R\&D outsourcing. Dai et al. [21] analyzed two typical cooperative behaviors, cartelization and cost-sharing contract, via a game-theoretical approach in a supply chain. They found that the effectiveness factor and technology difference lead to different preferences of modes, while setting appropriate subsidy rates requires observing factors and consumers' green consciousness. Wu et al. [3] considered the conditions in the collaborative R\&D of a supply chain and concluded that the optimal revenue sharing coefficient is positively correlated with the impact coefficient of product innovation success and is affected by the supplier's investment in the development of supporting components. Kim and Lim [6] investigated R\&D outsourcing in an innovation-driven supply chain. They found that there is a threshold of R\&D cost, beyond which the firms tend to outsource via hosting a contest. Davis-Sramek et al. [22] found that as a key resource and facilitator of knowledge generation, how does the $\mathrm{R} \& \mathrm{D}$ investment process affect enterprise's performance through an "chain of events" that includes differences in internal knowledge application and supply chain operations. Wu and Kao [23] investigated competitive and cooperative interactions in a closed-loop supply chain that includes an original equipment manufacturer and an independent remanufacturer. Lee et al. [24] studied the relationship between supply chain management practices. In the $\mathrm{R} \& \mathrm{D}$ and manufacturing environment in Malaysia, "relationship" is the intervention variable of strategic supplier partnership, customer relationship, information sharing, information quality, postponement, internal operation, and technological innovation. In a dynamic model, Lambertini [8] studied the optimal design of twopart tariffs in which two firms belonging to the same supply chain invest in $\mathrm{R} \& \mathrm{D}$ activities to improve the perceived quality of the final product. Noori-Daryan et al. [25] analyzed the optimal pricing, ordering, promised lead time, and supplier-selection policies of a pharmacological chain, under demand response time uncertainty. Taleizadeh et al. [26] considered two competing supply chains where both chains launch the same product under different brands to the market by applying different composite coordinating strategies. They [27] also examined the behavior of partners in a green supply chain facing with a group of purchasers whose demand is the function of a price, greenery degree, and refund rate.

\subsection{Differential Game and Its Application in Supply Chain} Management. Differential game is used to characterize and analyze the conflict in a dynamical system. The operational production of the manufacturer is usually multiperiod rather than single period. Thus, conducting research from the longrun and dynamic perspectives is much more realistic. $\mathrm{Zu}$ et al. [28] considered a two-echelon supply chain consisting of one manufacturer and one supplier that try to increase sustainable profits by making efforts on $\mathrm{CO}_{2}$ emission reduction in three progressive environment regulation situations using a Stackelberg differential game. Zhou and Ye [29] studied the optimal equilibrium strategies in dualchannel supply chains by using the differential game and discussed how the cooperative advertising contract and the cooperative advertising and emission reduction cost sharing contract affect the optimal strategies and coordination of dual-channel supply chains. Lu et al. [2] investigated the wholesale price contract and the consignment contract between a dominant retailer and her manufacturer under the effect of the dynamic advertising. Liu et al. [30] studied the optimal coordination strategy of a dynamic supply chain under uncertain conditions via a stochastic differential game model and explored how to coordinate the effort level of node enterprise to maximize supply chain profit. Yang and $\mathrm{Xu}$ [31] investigated a closed-loop supply chain (CLSC) with multiple members in a dynamic way; they developed a differential game model for the CLSC network based on differential variational inequality and showed that the differential variational inequality is equivalent to the nonlinear complementary problem. Zeng and Li [32] considered the cooperation strategies between the government and the members of a green supply chain; they discussed the differences in the optimal effort level, green degree of product, reputation, and the optimal benefit under the three situations by constructing a differential game model. Xiao and Huang [33] investigated the optimal return control problem in a closed-loop supply chain in the presence of stochastic return disturbance and fairness concern, by using a stochastic differential game model.

The present study is quite different from previous ones. First, most of the studies focused on the innovation in terms of quality of products; they neglected the consumers' innovation preference. This study analyzes the innovationdriven market demand and lets the innovation level of products to be the state variable. In particular, the optimal trajectory of innovation level is also derived. Second, the present study considers the innovation process dynamically rather than statically. Enterprise's innovation is a long-term dynamic process, which can be cross period. Therefore, decisions made in the prior period have certain reference effects on consumers' minds in the next period and will also 
influence relevant decisions made in the next period. Therefore, a dynamic approach to the problem is necessary. Third, the retailer was always responsible for the advertising of the products, rather than participating in the innovation. However, in this study, the retailer makes effort in the collection of consumer's knowledge and shares it with the manufacturer to improve the innovation level of products.

\section{Model Setting}

Consider a two-echelon supply chain system composed of a manufacturer and a retailer, in which the manufacturer occupies a dominant position. Consumers play an important role in the game because their preference for the innovation has a significant influence on market demand. Under the background where the influence becomes a pushing power of market demand, the manufacturer tends to enhance the innovation level of its products and actively invests in the $\mathrm{R} \& \mathrm{D}$ process. Compared with the manufacturer, the retailer has more advantage to learn and collect the consumer's knowledge (or preference) to the products. These knowledge can not only help the retailer to improve his selling strategy but also help the manufacturer's R\&D process which improves the innovation level of the products. To motivate the retailer to make greater effort to collect the consumer's knowledge, the manufacturer considers giving a discount within the transfer payment paid by the retailer. The mechanism of R\&D investment and collection of consumer's knowledge in the sustainable supply chain can be described as in Figure 1.

The retailer purchases the product from the manufacturer who charges a transfer payment (usually known as the wholesale price) for it. For the sake of the improvement of the innovation level, the manufacturer may stimulate the retailer through a discount of transfer payment. We consider three kinds of transfer payment contracts in this study.

(i) The wholesale price contract: the manufacturer does not stimulate the retailer to collect the consumer's knowledge. Instead, the manufacturer determines the optimal R\&D investment and the retailer determines the optimal retail price and efforts in consumer's knowledge collection to maximize their profit, respectively.

(ii) The incentive contract based on the effort in consumer's knowledge collection (IC for short): the manufacturer stimulates the retailer to make efforts in the collection consumer's knowledge by giving her a discount of the transfer payment. In this case, the manufacturer determines the optimal investment in the R\&D activities and rewards the retailer with a discount in the transfer payment as the retailer determines the efforts in the collection of the consumer's knowledge and the retail price.

(iii) The incentive contract based on the target effort in consumer's knowledge collection (ICT for short): the manufacturer commits to a target effort in the collection of consumer's knowledge to the retailer and rewards the retailer only if her effort in collecting consumer's knowledge exceeds the target. They determine the same variables as in the IC.

Nowadays, the consumers pay more attention to the level of product innovation as their personalized demands are increasing. It makes the enterprises' innovation become a continuous long-term process. Hence, we assume that the innovation level of the product is a time-varied dynamic process, denoted by $q(t)$. It is positively affected by the manufacturer's R\&D investment $x(t)$ and retailer's efforts in consumer's knowledge collection $y(t)$. When there is no $R \& D$ investment and effort toward the innovation, the innovation level will decay because the related technology of production and consumer's knowledge will depreciate over time. Therefore, the innovation level $q(t)$ evolves as

$$
\left\{\begin{array}{l}
\dot{q}(t)=\phi x(t)+\gamma y(t)-\tau q(t) \\
q(0)=q_{0} \geq 0
\end{array}\right.
$$

where $\phi$ and $\gamma$ are the sensitivities to the effort $x(t)$ and $y(t)$, respectively, $\tau$ is the decay rate of $q(t)$, and $q_{0}$ is the initial innovation level of the product. For the sake of simplicity, we let $\phi=1$ in this paper.

As mentioned in many previous studies $[34,35]$, with the development of innovation and consumers' increasing preference to the high-tech production, the market demand $D(t)$ for product is related to the innovation level of the products. We assume that there is a linear relationship between demand and innovation level of the product. To be consistent with previous studies $[9,36]$, our specification sets that demand also decreases with the retail price $p(t)$. Therefore, the market demand for product $D(t)$ can be written as

$$
D(t)=\alpha-p(t)+\beta q(t),
$$

where $\alpha$ is the market capacity and $\beta>0$ captures the consumer's sensitive to the innovation.

The R\&D and knowledge collection costs are defined as $C_{m}(x)=1 / 2 \lambda x^{2}$ and $C_{r}(y)=1 / 2 \eta y^{2}$, respectively, where $\lambda, \eta>0$ are the cost parameters. The quadratic cost function represents achieving a higher level of $\mathrm{R} \& \mathrm{D}$ and knowledge sharing; the cost will be increasingly accelerated $[9,35]$.

Table 1 presents the notations used in this paper.

Based on the above assumptions, the profit functions of the manufacturer, the retailer, and the whole supply chain are

$$
\begin{aligned}
& \pi_{\mathrm{m}}=T-\frac{1}{2} \lambda x(t)^{2}, \\
& \pi_{\mathrm{r}}=p(t) D(t)-T-\frac{1}{2} \eta y(t)^{2}, \\
& \pi_{\mathrm{sc}}=\pi_{\mathrm{m}}+\pi_{\mathrm{r}}=p(t) D(t)-\frac{1}{2} \lambda x(t)^{2}-\frac{1}{2} \eta y(t)^{2},
\end{aligned}
$$

respectively.

Based on the profit functions above, the three transfer payment contracts are specified as follows. In the wholesale price contract, the transfer payment $T=w D(t)$, where $T$ is the transfer payment for which manufacturer charges the 


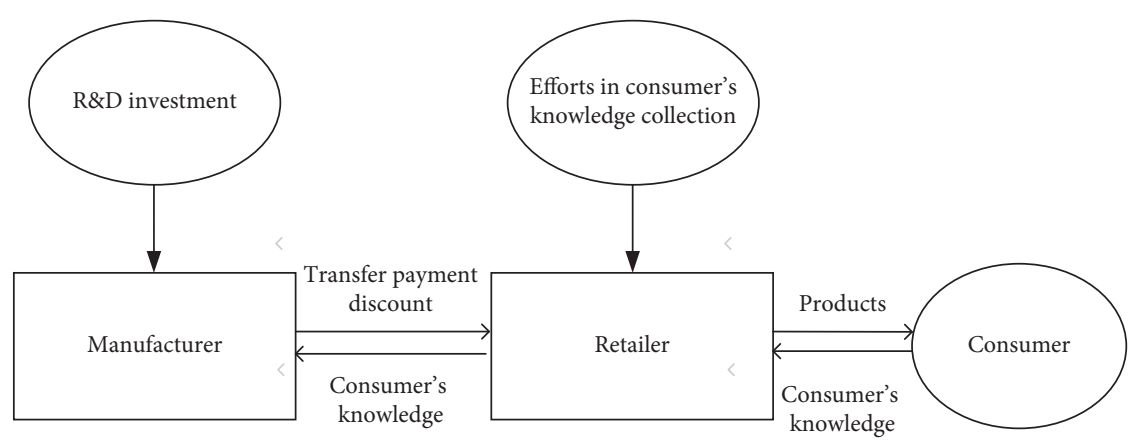

FIGURE 1: Mechanism of joint innovation and knowledge sharing and R\&D investment in supply chain.

TABLE 1: Notations and definitions.

\begin{tabular}{lc}
\hline Notation & Definition \\
\hline$x(t)$ & The manufacturer's R\&D investment \\
$y(t)$ & The retailer's efforts in consumer knowledge collection \\
$p(t)$ & The retail price of the product \\
$q(t)$ & The innovation level of the products \\
$D(t)$ & The market demand \\
$\alpha$ & The market capacity \\
$\beta$ & The consumer's sensitivity to the innovation \\
$\gamma$ & The innovation sensitivity to the retailer's efforts in \\
& collecting consumer's knowledge \\
$\delta$ & The marginal reward of the retailer's efforts in \\
$\tau$ & collecting consumer's knowledge \\
$y_{0}$ & The decay rate of the innovation level \\
$w$ & The target investment level of the consumer's \\
$\lambda$ & Thewledge \\
$\eta$ & The coefficient of the cost of R\&D \\
$T$ & The coefficient of the cost of the efforts toward \\
The transfer payment from the retailer to the & manufacturer \\
$\pi_{\mathrm{m}}$ & The unitary profit of the manufacturer \\
$\pi_{\mathrm{r}}$ & The unitary profit of the retailer \\
$\pi_{\mathrm{sc}}$ & The unitary profit of the supply chain \\
$r$ & The discount rate
\end{tabular}

retailer for the products and $w$ is the wholesale price. In the IC, the transfer payment $T=w D(t)-\delta y(t)$, where $\delta>0$ is the retailer's marginal reward offered by the manufacturer. In the ICT, the transfer payment $T=w D(t)-\delta\left(y(t)-y_{0}\right)$, where $y_{0}$ is the target level of consumer's knowledge committed by the manufacturer. The retailer can get the reward from the manufacturer only if $y(t)>y_{0}$.

In the infinite time horizon, the manufacturer and retailer are supposed to be risk-neutral and present the same discount rate $r(r>0)$. The wholesale price $w$ is the exogenous variable, whereas the $\mathrm{R} \& \mathrm{D}$ investment $x(t)$, the efforts in consumer's knowledge collection $y(t)$, and retail price $p(t)$ are the control variables. The innovation level $q(t)$ is the state variable.

Assumption 1. To ensure the existence of the equilibrium solutions of the model, we assume that $r \geq 2((\gamma \beta / \sqrt{2} \eta)-\tau)$.

\section{Model Solutions and Discussion}

Enterprise's $\mathrm{R} \& \mathrm{D}$ and innovation management is a longterm dynamic process, and the effect of innovation can be intertemporal. Both the manufacturer and the retailer are farsighted: they seek profit maximization in the long run considering the effects of the reference innovation. It is useful to introduce the dynamic framework into the research on innovation management in the supply chain. Therefore, we use the differential game to analyze this problem. To better compare the different innovation incentive mechanisms in the supply chain, we classified the innovation management into three transfer payment contracts: the wholesale price contract, the IC, and the ICT. Considering the different statuses of the manufacturer and the retailer in the supply chain, we use a Stackelberg game (the manufacturer as the leader and the retailer as the follower) to analyze the different kinds of the contracts.

4.1. Benchmark Model. Before comparing the three kinds of contracts, we investigate the centralized scenario, in which the manufacturer and retailer are vertically integrated as a whole system (denoted by superscript C). The optimization problem is a standard optimal control problem given as

$$
\begin{aligned}
\max _{p(t), x(t), y(t)} J_{\mathrm{sc}}^{\mathrm{C}}= & \int_{0}^{\infty} e^{-r t}\left[p(t) D(t)-\frac{1}{2} \lambda x(t)^{2}\right. \\
& \left.-\frac{1}{2} \eta y(t)^{2}\right] \mathrm{d} t .
\end{aligned}
$$

Denote the optimal net profit of supply chain as $V_{s}^{\mathrm{C}}(q)$, by using the dynamic programming theory; then, for all $q(t) \geq 0, \quad V_{\mathrm{s}}^{\mathrm{C}}(q)$ satisfies the Hamilton-Jacobi-Bellman equation below:

$$
r V_{\mathrm{s}}^{\mathrm{C}}(q)=\max _{p, x, y}\left[p D-\frac{1}{2} \lambda x^{2}-\frac{1}{2} \eta y^{2}+V_{\mathrm{s}}^{\mathrm{C}^{\prime}}(q)(x+\gamma y-\tau q)\right] .
$$

Differentiate the HJB equation with respect to $p, x$, and $y$, and the optimal strategies can be expressed as 


$$
\begin{aligned}
& p^{\mathrm{C} *}=\frac{\beta q+\alpha}{2}, \\
& x^{\mathrm{C} *}=\frac{V_{\mathrm{s}}^{\mathrm{C}^{\prime}}}{\lambda}, \\
& y^{\mathrm{C} *}=\frac{\gamma V_{\mathrm{s}}^{\mathrm{C}^{\prime}}}{\eta} .
\end{aligned}
$$

It can be seen that the optimal function depending on $q$ is the solution of the HJB equation. To work out these solutions, we set the general form of the function as $V_{\mathrm{s}}^{\mathrm{C}}(q)=f_{1} q^{2}+f_{2} q+f_{3}$; then, $V_{\mathrm{s}}^{\mathrm{C}}(q)=2 f_{1} q+f_{2}$, and we substitute them into the equations above. Solve $f_{1}, f_{2}$, and $f_{3}$ through the simultaneous linear equations; then, the optimal strategies can be expressed as in Proposition 1 as follows (for the proof, see the Appendix).

Proposition 1. In the centralized model, the optimal equilibrium strategies for the R\&D investment, the efforts in consumer's knowledge collection, and the retail price are

$$
\left\{\begin{array}{l}
x^{\mathrm{C} *}(t)=\frac{\eta(r+2 \tau)-\sqrt{\eta^{2}(r+2 \tau)^{2}-2 \eta \beta^{2}\left(\eta / \lambda+\gamma^{2}\right)}}{2\left(\eta+\lambda \gamma^{2}\right)} q+\frac{\beta \alpha}{\lambda r+\sqrt{\lambda^{2}(r+2 \tau)^{2}-2 \lambda \beta^{2}\left(\left(\eta+\lambda \gamma^{2}\right) / \eta\right)}} \\
y^{\mathrm{C} *}(t)=\frac{\gamma \lambda(r+2 \tau)-\gamma \sqrt{\lambda^{2}(r+2 \tau)^{2}-2 \lambda \beta^{2}\left(\left(\eta+\lambda \gamma^{2}\right) / \eta\right)}}{2\left(\eta+\lambda \gamma^{2}\right)} q+\frac{\gamma \beta \alpha}{\eta r+\sqrt{\eta^{2}(r+2 \tau)^{2}-2 \eta \beta^{2}\left(\left(\eta+\lambda \gamma^{2}\right) / \eta\right)}}, \\
p^{\mathrm{C} *}(t)=\frac{\beta q+\alpha}{2},
\end{array}\right.
$$

respectively, in which $q=q^{C}+\left(q_{0}-q^{C}\right) e^{-\tau t}$, where $q^{C}=$ $\left(x^{C *} / \tau\right)+\left(\gamma y^{C *} / \tau\right)$.

It should be noted that there is a specific condition to ensure that $V_{\mathrm{s}}^{\mathrm{C}}(q)=f_{1} q^{2}+f_{2} q+f_{3}$ equals the value function of the supply chain, so that the solutions in Proposition 1 are the optimal strategies. The condition is

$$
\lim _{t \longrightarrow \infty} e^{-r t} V(q(t))=0
$$

where $q(t)$ can be calculated by inserting the optimality into equation (1). We thus obtain the optimal path of the innovation level as follows:

$$
q=q^{\mathrm{C}}+\left(q_{0}-q^{\mathrm{C}}\right) e^{-\tau t}, \quad q(0)=q_{0},
$$

where $q^{\mathrm{C}}$ is the steady state of the innovation level given by $q^{\mathrm{C}}=\left(x^{\mathrm{C} *} / \tau\right)+\left(\gamma y^{\mathrm{C} *} / \tau\right)$.

Thus, the optimal R\&D investment, efforts in collection of consumer's knowledge, and the retail price in the centralized scenario can be obtained.

Proposition 1 states that the optimal R\&D investment, the optimal efforts in collection of consumer's knowledge, and the optimal retail price are linear and increasing in the state variable. It implies that when the innovation level increases, the decision makers increase their own decision variables to benefit from the consumer's preference on innovation level of products. The behaviors thereby improve the profit of supply chain greatly.

4.2. Decentralized Supply Chain Model Based on Wholesale Price Contract. In the decentralized scenario with the wholesale price contract (denoted by superscript DW), the manufacturer and retailer make their own decisions to maximize their profits, with the manufacturer acting as a
Stackelberg leader. The sequence of decisions is as follows: the manufacturer first selects the optimal R\&D investment $x(t)$, and then the retailer chooses the optimal consumer knowledge investment $y(t)$ and retail price $p(t)$. The only regulatory mechanism in this situation is based on the market, namely, consumers have strong innovation preference, and they tend to pay more for the products with high innovation level. This market preference provides power to push the supply chain to make much more efforts in innovation and to produce high-tech product. In this situation, the decision problems of the manufacturer and the retailer are, respectively, expressed as

$$
\begin{aligned}
\max _{x(t)} J_{\mathrm{m}}^{\mathrm{DW}} & =\int_{0}^{\infty} e^{-r t}\left(w D-\frac{\lambda}{2} x^{2}(t)\right) \mathrm{d} t, \\
\max _{y(t), p(t)} J_{\mathrm{r}}^{\mathrm{DW}} & =\int_{0}^{\infty} e^{-r t}\left((p(t)-w) D-\frac{\eta}{2} y^{2}(t)\right) \mathrm{d} t .
\end{aligned}
$$

Denote the optimal net profit of the manufacturer and the retailer at time $t$ as $V_{\mathrm{m}}^{\mathrm{DW}}$ and $V_{\mathrm{r}}^{\mathrm{DW}}$, respectively. By using the dynamic programming theory, for all $q(t) \geq 0, V_{\mathrm{m}}^{\mathrm{DW}}$ and $V_{\mathrm{r}}^{\mathrm{DW}}$ satisfy the Hamilton-Jacobi-Bellman equations below:

$$
\begin{aligned}
r V_{\mathrm{m}}^{\mathrm{DW}}(q)= & \max _{x}\left[w(\alpha-p+\beta q)-\frac{\lambda}{2} x^{2}+V_{\mathrm{m}}^{\mathrm{DW}^{\prime}}(x+\gamma y-\tau q)\right] \\
r V_{\mathrm{r}}^{\mathrm{DW}}(q)= & \max _{y, p}\left[(p-w)(\alpha-p+\beta q)-\frac{\eta}{2} y^{2}\right. \\
& \left.+V_{\mathrm{r}}^{\mathrm{DW}^{\prime}}(x+\gamma y-\tau q)\right] .
\end{aligned}
$$


Differentiate the HJB equations with respect to $x(t)$, $y(t)$, and $p(t)$, and the optimal results can be expressed as

$$
\begin{aligned}
& y^{\mathrm{DW} *}=\frac{\gamma V_{r}^{\mathrm{DW}^{\prime}}}{\eta}, \\
& x^{\mathrm{DW} *}=\frac{V_{\mathrm{m}}^{\mathrm{DW}^{\prime}}}{\lambda}, \\
& p^{\mathrm{DW} *}=\frac{\beta q+\alpha+w}{2} .
\end{aligned}
$$

It can be seen that the optimal functions depending on $q$ are the solutions of the HJB equations. To work out these solutions, we set the general forms of these functions as $V_{\mathrm{m}}^{\mathrm{DW}}(q)=m_{1} q+m_{2}, V_{\mathrm{r}}^{\mathrm{DW}}(q)=h_{1} q^{2}+h_{2} q+h_{3}$; then, $V_{\mathrm{m}}^{\mathrm{DW}^{\prime}}(q)=m_{1}, V_{\mathrm{r}}^{\mathrm{DW}^{\prime}}(q)=2 h_{1} q+h_{2}$, and we substitute them into the equations above. We can solve the $m_{1}, h_{1}$, and $h_{2}$ through the simultaneous linear equations; then, the optimal investment and efforts of the manufacturer and retailer in the wholesale contract can be expressed as in Proposition 2 as follows (for the proof, see the Appendix).

Proposition 2. In the decentralized scenario with the wholesale price contract, the manufacturer's optimal R\&D investment, the retailer's the optimal efforts in collection of consumer's knowledge, and the optimal retail price are

$$
\left\{\begin{array}{l}
x^{\mathrm{DW} *}(t)=\frac{\beta w}{\lambda(r+\Delta)}, \\
y^{\mathrm{DW} *}(t)=\frac{r+2 \tau-\Delta}{2 \gamma} q+\frac{\gamma \lambda \beta(\alpha-w)+(\beta \eta w((r+\Delta)-\Delta) / \gamma(r+\Delta))}{\eta^{2} \lambda(r+\Delta)} \\
p^{\mathrm{DW} *}(t)=\frac{\beta q+\alpha+w}{2}
\end{array}\right.
$$

respectively, where $\Delta=\sqrt{(r+2 \tau)^{2}-\left(2 \gamma^{2} \beta^{2} / \eta\right)}$, in which $q=q^{D W}+\left(q_{0}-q^{D W}\right) e^{-\tau t}, \quad$ where $\quad q^{D W}=\left(x^{D W *} / \tau\right)+$ $\left(\gamma y^{D W *} / \tau\right)$.

From Proposition 2, we can see that the manufacturer's optimal R\&D investment is increasing with consumer sensitivity to the innovation and wholesale price, whereas it is decreasing in coefficients of the cost of the manufacturer's $\mathrm{R} \& \mathrm{D}$ investment and retailer's efforts in consumer knowledge collection. It is reasonable that the manufacturer invests more in the $R \& D$ activities as the consumer has higher innovation sensitivity, and the higher wholesale price can fund more money for him to invest more in R\&D. Conversely, the cost coefficient of R\&D investment would cut down the optimal $\mathrm{R} \& \mathrm{D}$ investment. Interestingly, we found that the $x^{\mathrm{DW} *}$ is decreasing with the coefficient of the cost of retailer's efforts in consumer knowledge collection. It implies that if the retailer's effort is relatively high, then the manufacturer intends to invest more to keep the innovation level.

The retailer's effort and the retail price are linear and increasing with the innovation level. The positive relationship between the retail price and innovation level can be traced back to the fact that improving innovation is costly and that higher innovation level commands a higher willingness of the consumer to pay for it. The retailer's optimal efforts are also increasing with the innovation level; it follows that the innovation level motivates the retailer to make more efforts to collect consumer's knowledge, so that the retailer can make more profit from the innovation of the products. Knowledge Collection Contract. In the decentralized scenario with the consumer knowledge investment contract (denoted by superscript DC), the manufacturer and retailer make their own decisions to maximize their profits, with the manufacturer acting as a Stackelberg leader. The sequence of decisions is as follows: the manufacturer first selects the optimal R\&D investment $x^{\mathrm{DC}}(t)$, and then the retailer chooses the optimal effort in collection of consumer knowledge $y^{\mathrm{DC}}(t)$ and retail price $p^{\mathrm{DC}}(t)$. The decision problems of the manufacturer and retailer are, respectively, expressed as

$$
\begin{aligned}
\max _{x(t)} J_{\mathrm{m}}^{\mathrm{DC}} & =\int_{0}^{\infty} e^{-r t}\left(w D-\delta y(t)-\frac{\lambda}{2} x^{2}(t)\right) \mathrm{d} t \\
\max _{y(t), p(t)} J_{\mathrm{r}}^{\mathrm{DC}} & =\int_{0}^{\infty} e^{-r t}\left((p-w) D+\delta y(t)-\frac{\eta}{2} y^{2}(t)\right) \mathrm{d} t .
\end{aligned}
$$

By using the dynamic programming theory, for all $q \geq 0$, the value function $V_{\mathrm{m}}^{\mathrm{DC}}(q), V_{\mathrm{r}}^{\mathrm{DC}}(q)$ should meet the HJB equations below:

$$
\begin{aligned}
r V_{\mathrm{m}}^{\mathrm{DC}}(q)= & \max _{x}\left[w(\alpha-p+\beta q)-\delta y-\frac{\lambda}{2} x^{2}\right. \\
& \left.+V_{\mathrm{m}}^{\mathrm{DC}^{\prime}}(x+\gamma y-\tau q)\right], \\
r V_{\mathrm{r}}^{\mathrm{DC}}(q)= & \max _{y, p}\left[(p-w)(\alpha-p+\beta q)+\delta y-\frac{\eta}{2} y^{2}\right. \\
& \left.+V_{\mathrm{r}}^{\mathrm{DC}^{\prime}}(x+\gamma y-\tau q)\right] .
\end{aligned}
$$


Differentiating the HJB equations with respect to $x, y$, and $p$, the optimal results can be expressed as

$$
\begin{aligned}
& x^{\mathrm{DC} *}=\frac{V_{\mathrm{m}}^{\mathrm{DC}}}{\lambda}, \\
& y^{\mathrm{DC} *}=\frac{\delta+\gamma V_{\mathrm{r}}^{\mathrm{DC}^{\prime}}}{\eta}, \\
& p^{\mathrm{DC} *}=\frac{\beta q+\alpha+w}{2} .
\end{aligned}
$$

We can make the following comments on the above reaction functions. (i) The retail price increases with the consumer's sensitivity to the innovation as it is intuitively reasonable to suppose that the innovation preference commands a higher retail price. (ii) The manufacturer's value function must be increasing with the innovation level. (iii) The retailer's effort in collection of the consumer's knowledge is increasing with the marginal reward.

Similar to Section 4.2, we have the following proposition.

Proposition 3. In the decentralized scenario with the consumer knowledge collection contract, the manufacturer's optimal R\&D investment, the retailer's the optimal effort in collection of consumer's knowledge, and the optimal retail price are

$$
\left\{\begin{array}{l}
x^{\mathrm{DC} *}(t)=\frac{\gamma w \beta-\delta((2 \tau+r)-\Delta)}{\lambda \gamma(r+\Delta)} \\
y^{\mathrm{DC} *}(t)=\frac{r+2 \tau-\Delta}{2 \gamma} q+\frac{2 \lambda \delta(r+\tau)+\gamma\left(\lambda \beta(\alpha-w)+4 j_{1} g_{1}\right)}{\lambda \eta(r+\Delta)} \\
p^{\mathrm{DC} *}(t)=\frac{\beta q+\alpha+w}{2}
\end{array}\right.
$$

respectively, where $j_{1}=\left(\eta(r+2 \tau-\Delta) / 4 \gamma^{2}\right), \quad g_{1}=(\gamma w \beta-$ $\delta(2 \tau+r)+\delta \Delta) /(\gamma r+\gamma \Delta), \quad q=q^{D C}+\left(q_{0}-q^{D C}\right) e^{-\tau t}$, $\Delta=\sqrt{\left((r+2 \tau)^{2}-2 \gamma^{2} \beta^{2} / \eta\right)}$, in which $q^{D C}=\left(x^{D C *} / \tau\right)+$ $\left(\gamma y^{D C *} / \tau\right)$.

From Proposition 3, we can see that the manufacturer's optimal $\mathrm{R} \& \mathrm{D}$ investment is increasing with consumer's sensitivity to the innovation and wholesale price, whereas it is decreasing with coefficients of the cost of the manufacturer's R\&D investment and the marginal reward to the retailer. The manufacturer motivates the retailer via the discount in the transfer payment, so that he would lower his $\mathrm{R} \& \mathrm{D}$ investment to save his own profit.

4.4. Decentralized Supply Chain Model Based on Target Effort of Consumer's Knowledge Contract. In the decentralized scenario with the target effort of consumer's knowledge contract (denoted by superscript DT), the manufacturer and retailer make their own decisions to maximize their profits, with the manufacturer acting as a Stackelberg leader. In this contract, the manufacturer assigns a target effort $y_{0}$ of consumer knowledge based on the retailer's historical appearance. The manufacturer will reward the retailer only if the retailer's investment in collection of the consumer's knowledge exceeds $y_{0}$. The sequence of decisions is as follows: the manufacturer first selects the optimal R\&D investment $x^{\mathrm{DT}}(t)$, and then the retailer chooses the optimal consumer knowledge investment $y^{\mathrm{DT}}(t)$ and retail price $p^{\mathrm{DT}}(t)$. The decision problems of the manufacturer and retailer are, respectively, expressed as

$$
\begin{aligned}
\max _{x(t)} J_{\mathrm{m}}^{\mathrm{DT}}= & \int_{0}^{\infty} e^{-r t}\left(w D-\delta\left(y(t)-y_{0}\right)^{+}-\frac{\lambda}{2} x^{2}(t)\right) \mathrm{d} t \\
\max _{y(t), p(t)} J_{\mathrm{r}}^{\mathrm{DT}}= & \int_{0}^{\infty} e^{-r t}((p(t)-w) D \\
& \left.+\delta\left(y(t)-y_{0}\right)^{+}-\frac{\eta}{2} y^{2}(t)\right) \mathrm{d} t .
\end{aligned}
$$

With the similar arguments as in Sections 4.2 and 4.3, we have the following result.

Proposition 4. In the decentralized scenario with the consumer knowledge collection contract with effort target, the manufacturer's optimal R\&D investment, the retailer's the optimal efforts in collection of consumer's knowledge, and the optimal retail price are

$$
\left\{\begin{array}{l}
x^{\mathrm{DT} *}(t)=\frac{\gamma w \beta-\delta(2 \tau+r-\Delta)}{\lambda \gamma(r+\Delta)} \\
y^{\mathrm{DT} *}(t)=\operatorname{Max}\left\{\frac{2 \tau+r-\Delta}{2 \gamma} q+\frac{\delta}{\eta}+\frac{\gamma\left(4 \lambda \gamma \delta l_{1}+4 \eta l_{1} k_{1}+\eta \lambda \beta(\alpha-w)\right)}{\lambda \eta^{2}(\Delta+r)}, y_{0}\right\} \\
p^{\mathrm{DT} *}(t)(t)=\frac{\beta q+\alpha+w}{2}
\end{array}\right.
$$


respectively, where $l_{1}=\left(\eta(2 \tau+r-\Delta) / 4 \gamma^{2}\right), \quad k_{1}=(\gamma w \beta-$ $\delta(2 \tau+r-\Delta) / \gamma(r+\Delta)), q=q^{D T}+\left(q_{0}-q^{D T}\right) e^{-\tau t}$, in which $\Delta=\sqrt{\left((r+2 \tau)^{2}-2 \gamma^{2} \beta^{2} / \eta\right)} \quad$ and $\quad q^{D T}=\left(x^{D T *} / \tau\right)+$ $\left(\gamma y^{D T *} / \tau\right)$.

We found that the effort target committed by the manufacturer only affects the retailer through its objective function; it has no influence on the efforts of the retailer and the $R \& D$ investment of the manufacturer. The target only affects the retailer's effort decision only through the objective function, i.e., the net profit. To earn more profit, the retailer needs to make more efforts than the target. The amount of the reward affects the participators' action through their investment and effort and the objective function according to the optimal strategies.

\section{Comparison and Analysis}

According to the analysis of the three kinds of contracts, we compare the different game equilibria of $\mathrm{R} \& \mathrm{D}$ investments and present the relations of the steady-state optimal efforts in the collection of consumer's knowledge, the retail prices, and the value functions of the manufacturer and the retailer in each contract, respectively.

Theorem 1. In the decentralized scenario, the manufacturer's optimal R\&D investments hold for $x^{D T *}=x^{D C *}<x^{D W *}$, and they are state-independent. Moreover, $\quad x^{D T *}=x^{D C *}=x^{D W *}-((\delta((2 \tau+r)-$ $\left.\left.\left.\left.\sqrt{\left((r+2 \tau)^{2}-2 \gamma^{2} \beta^{2} / \eta\right.}\right)\right)\right) /\left(\lambda \gamma\left(r+\sqrt{\left((r+2 \tau)^{2}-2 \gamma^{2} \beta^{2} / \eta\right)}\right)\right)\right)$.

According to the analysis of these three contracts, the manufacturer's optimal R\&D investments remain the same in IC and ICT. The reason is that although the manufacturer commits a target to the retailer for her efforts in the collection of the consumer's knowledge, this target has no effect on the R\&D investment decisions of the manufacturer himself. However, In the IC and ICT situation, the manufacturer rewards the retailer for her efforts; hence, he has to cut down his R\&D investment to save his own profit. Notice that the $x^{\mathrm{DW} *}-x^{\mathrm{DC} *}$ is proportional to the discount rate $\delta$; the more reward given by the manufacturer, the less $R \& D$ investment he will make.

Theorem 2. In the decentralized scenario, the retailer's steady-state optimal efforts in the collection of the consumer's knowledge hold for $y_{\infty}^{D W *}<y_{\infty}^{D T *}<y_{\infty}^{D C *}$.

The retailer makes least efforts in the collection of the consumer's knowledge in the wholesale price contract, since the retailer has no incentive to do such things. Contrarily, the retailer is motivated by the manufacturer significantly under the IC; hence, she devoted most in the collection of consumer's knowledge. If the manufacturer commits a target to the retailer for her effort, the retailer's optimal decision will depend on the target and the marginal reward, and thus it will be strictly lower than the one under the IC and larger than the one under the wholesale price contract.

Theorem 3. In the decentralized scenario, the steady-state optimal retail prices hold for $p_{\infty}^{D W *}<p_{\infty}^{D T *}<p_{\infty}^{D C *}$.

The retail price is highest in the IC situation; since the manufacturer rewards the retailer for her efforts in the collection of the consumer's knowledge, it motivates the retailer to make more efforts. The consequence is that the cost of supply chain members becomes higher, and then the retail price is also high. Contrarily, under the traditional wholesale price contract, the cost of innovation is not so high as in other situations, so the retail price is lowest under the three situations. However, this means that the innovation level is also lower than the ones under other contracts.

Theorem 4. In the decentralized scenario, the manufacturer's steady-state optimal profit value functions hold for $V_{m \infty}^{D C}<V_{m \infty}^{D W}<V_{m \infty}^{D T}$.

In the ICT situation, the manufacturer not only invests in his own $\mathrm{R} \& \mathrm{D}$ investment but also motivates the retailer to make more efforts to collect the consumer's knowledge. He thus gains the highest profit among the three contracts. In the IC situation, the manufacturer rewards the retailer for her efforts; hence, his profit may be reduced. We have the similar result about the relationship between the profit of the retailer in the three contracts as follows.

Theorem 5. In the decentralized scenario, the retailer's steady-state optimal profit value functions hold for $V_{r \infty}^{D T}<V_{r \infty}^{D W}<V_{r \infty}^{D C}$

Theorem 6. The supply chain's steady-state optimal profit value functions hold for $V_{s 00}^{D T}<V_{s \infty}^{D W}<V_{s \infty}^{D C}<V_{s}^{C}$, where $V_{s \infty}^{D T}=V_{m \infty}^{D T}+V_{r \infty}^{D T}, \quad V_{s \infty}^{D W}=V_{m \infty}^{D W}+V_{r \infty}^{D W}, \quad$ and $V_{s \infty}^{D C}=$ $V_{m \infty}^{S \infty}+V_{r \infty}^{D C}$

Theorem 6 illustrates that the supply chain can attain its maximum profit in the centralized decision scenario, since the members make the decisions as a whole. To our surprise, the value of the supply chain in the ICT situation is the least. The manufacturer commits a target so that it can be regarded as a reward or penalty, and the retailer has to make more effort to gain the reward instead of suffering a penalty, which makes $V_{\mathrm{r}}^{\mathrm{DT}}$ sufficiently small. Contrarily, the retailer only gains the reward without penalty in the wholesale price contract. Meanwhile, the manufacturer has to pay for the retailer's efforts for her knowledge of consumers; hence, the manufacturer's optimal profit value function gets sufficiently small.

The specific expressions of the enterprises' optimal decisions and profits are calculated by Wolfram Mathematica 11.2 , and the solutions are too complicated to be shown in our paper. We refrain from printing them, and they are available from the authors. Therefore, we omit the proofs of Theorems 2-6. 


\section{Numerical Results}

To better understand the long-term relationship between the equilibria of the three kinds of contracts and the benchmark model, simulations and sensitivity analysis of the models are produced in this section. The main object of this section is obtaining the relationship among net profit, R\&D investment, efforts in consumer's knowledge collection, and retail price by considering different transfer payment contracts. The assignment of parameters can be set as $\alpha=10, \beta=0.6$, $\gamma=0.6, \delta=0.2, \tau=0.8, y_{0}=1, q_{0}=0, w=3, \lambda=1, \eta=1$, and $r=0.1$.

The simulations of the retailer's optimal efforts in the collection of the consumer's knowledge are shown in Figure 2(a), in which we can see that the retailer's effort under the wholesale price contract is lowest. Since there is no reward offered by the manufacturer, the retailer does not voluntarily make more efforts to collect consumer's knowledge than is necessary to ensure her own profit. Moreover, the effort target committed by the manufacturer motivates the retailer efficiently, since $y^{\mathrm{DT} *}>y^{\mathrm{DW} *}$ is shown in the figure. However, the reward offered by the manufacturer can motivate the retailer to make much more effort in the collection of consumer's knowledge. $y^{\mathrm{DC} *}-y^{\mathrm{DT} *}>y^{\mathrm{DT} *}-y^{\mathrm{DW} *}$ shows that the transfer payment discount according to the retailer's effort is more efficient than the effort target committed by the manufacturer. Combining Proposition 4, it implies that the retailer prefers the reward even if the target is not high, and the retailer is more autonomous to make effort under the IC to maximize her profit. The retailer's optimal effort under the IC is even higher than the one in the centralized decision scenario, that is, $y^{\mathrm{DC} *}>y^{\mathrm{C} *}$, before they reach their steady states. It shows that the reward offered by the manufacturer is very attractive to the retailer; hence, she pays very much to collect the consumer's knowledge to gain the reward. Figure 2(a) also shows that the steady states of $y^{\mathrm{DC} *}$ and $y^{\mathrm{C} *}$ are very close to each other. Since the supply chain can always achieve the highest profit rate in the centralized decision scenario, the retailer realizes that she could benefit from that, so she must work hard in the collection of consumer's knowledge; hence, $y^{\mathrm{C} *}$ increases sharply over time even when it is lower than $y^{\mathrm{DC} *}$ initially. The result shows that the IC is the most efficient contract to stimulate the retailer to make effort and cooperate with the manufacturer for the product's innovation.

The simulations of the optimal retail prices are shown in Figure 2(b). The target committed by the manufacturer leads only to a small increase in the price than the case in the supply chain without coordination mechanisms. The reward offered by the manufacturer makes the price increase sharply in IC situation. In the centralized scenario, the optimal price is lower than the ones in decentralized scenario initially; specifically, $0<t<2.55$ under the setting of parameters. The reason is that the transfer payments among supply chain members can significantly increase retail prices in the initial stage and make the optimal prices approach the steady state early. The optimal price in the centralized scenario sharply increases in the early stage and becomes higher than $p^{\mathrm{DW} *}$ when $t>2.55$ and higher than $p^{\mathrm{DT} *}$ when $t>2.8$. Finally, it tends to exceed the steady state of $p^{\mathrm{DC} *}$. In centralized scenario, the members may make more effort to gain the profit for the whole supply chain; hence, the retail price would be higher than the other cases.

The simulation of the optimal innovation levels is shown in Figure 3(a). It is obvious that the innovation level in the centralized scenario increases rapidly; it is significantly higher than the counterparts in decentralized scenarios. The supply chain members make the decisions as a whole; combining Theorem 1 and Figure 2(a), we can see that the $\mathrm{R} \& \mathrm{D}$ investment, effort in collection of consumer's knowledge, and retail price are highest in this scenario. It leads to that the innovation level of product is highest as well. Considering the decentralized scenario, IC makes the innovation level higher than the other two contracts do. The reason is the retailer makes the most effort under this contract according to Theorem 2. It implies that the retailer's effort in collection of consumer's knowledge influences the innovation level product significantly. The target committed by the manufacturer leads to a small increase in the innovation level than the case that there is no coordination mechanism in the supply chain. The reward offered by the manufacturer makes the innovation level increase sharply in IC situation.

The simulation of the optimal profit value functions of supply chain is shown in Figure 3(b). The value function of the centralized scenario is much more higher than the counterparts in the decentralized scenario. The supply chain members make decisions as a whole; this can increase the profit of the supply chain. The value function in IC situation is highest in the decentralized scenario. It implies that a reward offered by the manufacturer can make more profit of the supply chain. On the other hand, the retailer's effort in collection of consumer's knowledge dominates the innovation level under IC; the high innovation level of product can attract more consumers and create larger market demands; subsequently, it increases the profit of whole supply chain. However, the value function in the ICT situation is significantly lower than the other two in decentralized scenario because the manufacturer's target plays a role as a reward or penalty at the same time; hence, it may lower the profit of the supply chain.

In order to clarify the influence of innovation level on the profit of supply chain under different contracts, we make a sensitivity analysis of the coefficient $\beta$ related to innovation level in demand function. The increase in $\beta$ means that consumers are becoming more sensitive to the level of innovation and are more likely to purchase the innovative or high-tech products. We learned some interesting insights from Figure 4(a). (i) If $\beta=0$, it shows that $V^{\mathrm{DW} *}=V^{\mathrm{DT} *}=V^{\mathrm{DC} *}$. The incentive contracts have no contribution to the profit of supply chain if consumers are indifferent to the innovation of product. (ii) Considering $V^{\mathrm{DC} *}-V^{\mathrm{DT} *}$, the difference of profit value functions under IC and ICT increases rapidly with $\beta$. We conclude that, comparing to the effort target, the reward offered by the manufacturer is much more beneficial to the profit of supply chain. It suggests that for the sake of the whole supply chain, 


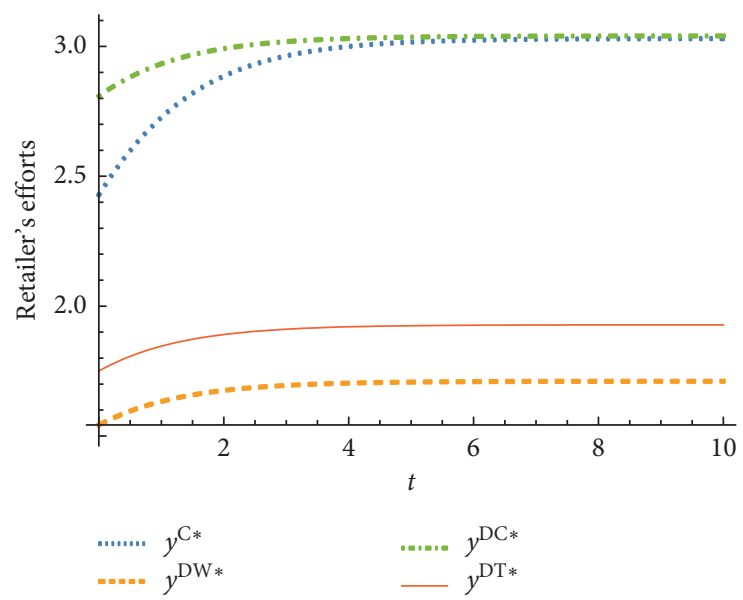

(a)

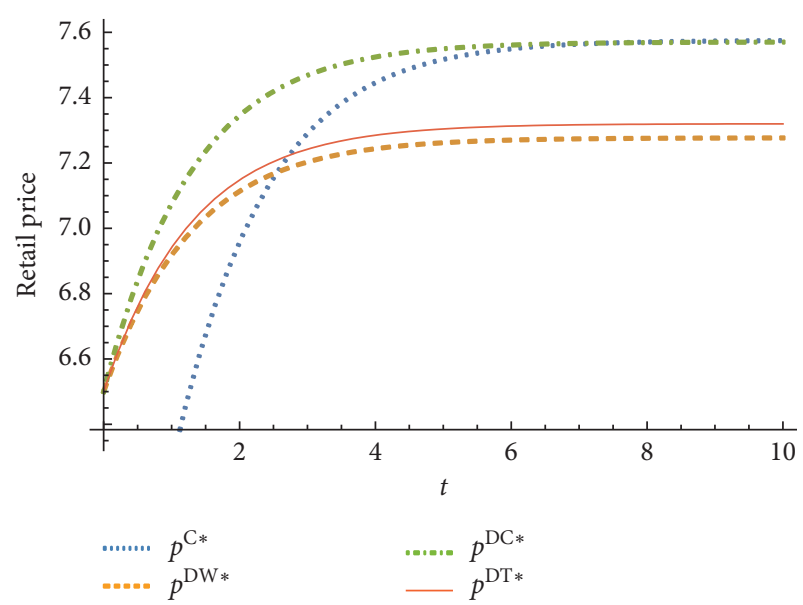

(b)

FIGURE 2: Optimal efforts of retailer and retail prices. (a) Retailer's optimal efforts. (b) Optimal retail price.

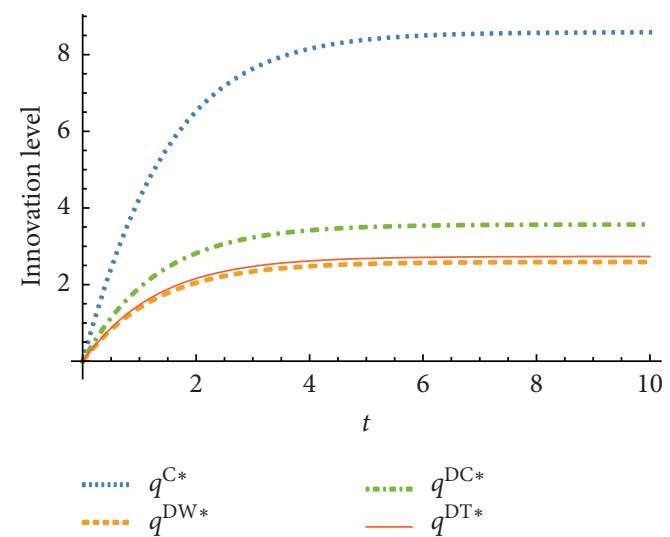

(a)

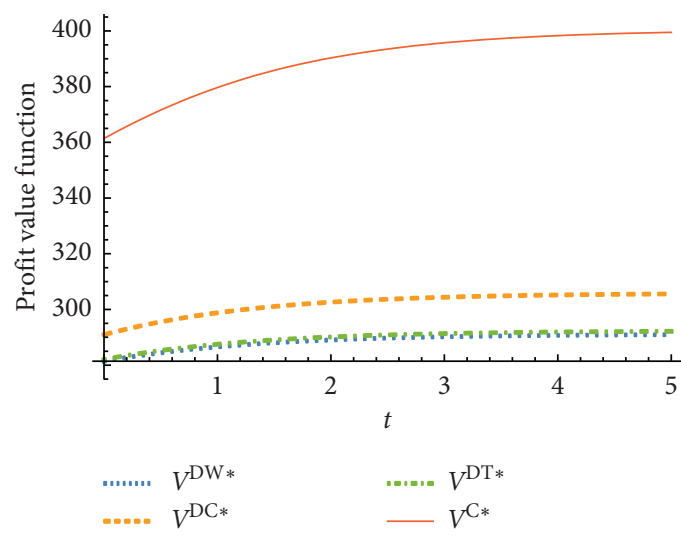

(b)

FIGURE 3: Optimal innovation levels and supply chain's profits. (a) Optimal innovation level. (b) Optimal profit value of supply chain.

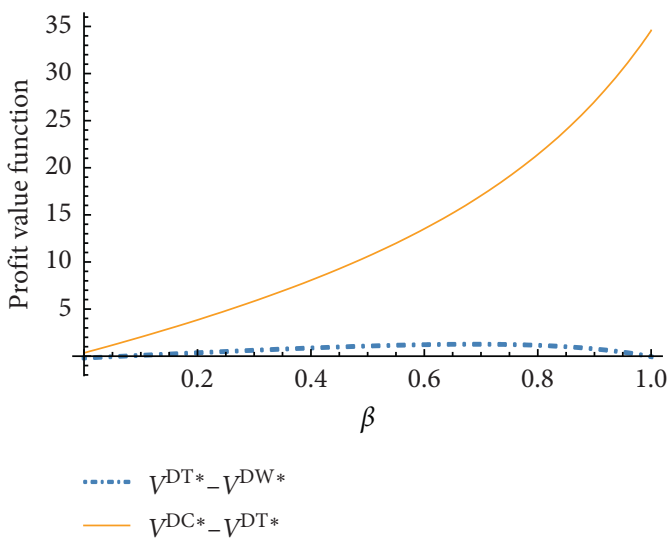

(a)

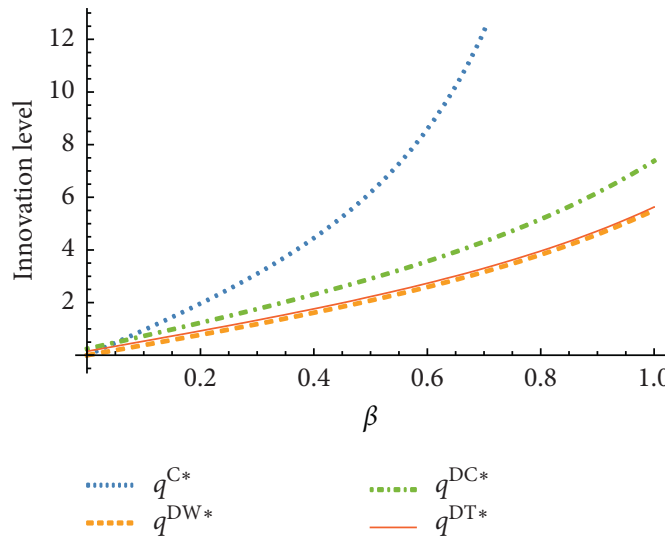

(b)

FIGURE 4: Optimal innovation levels and supply chain's profits w.r.t. $\beta$. (a) Optimal profit value functions of supply chain with varying $\beta$. (b) Optimal innovation levels with varying $\beta$. 

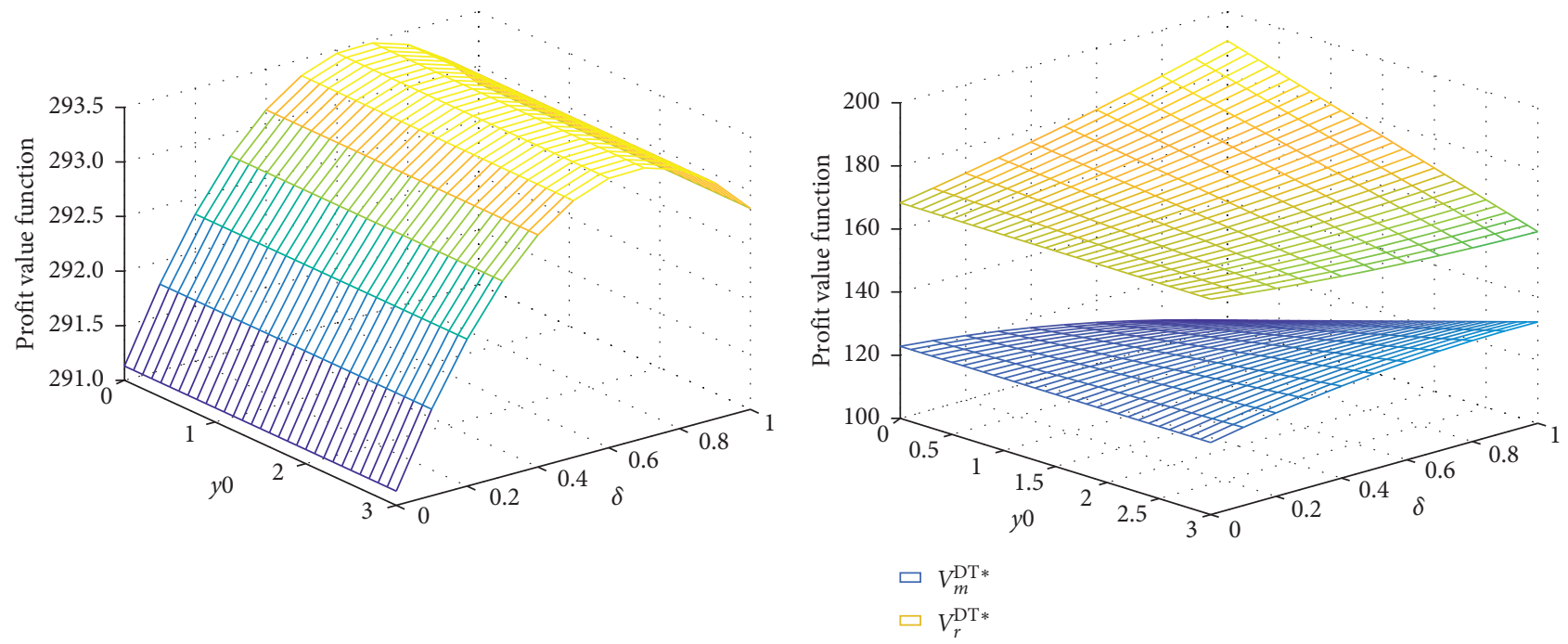

(a)

(b)

Figure 5: Optimal profit value functions w.r.t. $\beta$ and $y_{0}$. (a) Optimal profit value of supply chain. (b) Optimal profits of manufacturer and retailer.

the manufacturer should choose IC rather than ICT if the consumers are sensitive to the innovation level. (iii) Considering $V^{\mathrm{DT} *}-V^{\mathrm{DW} *}$, the difference of profit value functions under ICT and the wholesale price contract is not monotonic with respect to $\beta$. It increases fist and then decreases to 0 as $\beta$ tends to 1 . It shows that when the consumers do not care or when they are extremely sensitive to the innovation level of product, there is no difference between ICT and the wholesale price contract. The ICT can be more beneficial to the supply chain only if the consumers' innovation sensitivity is medium. Therefore, our model suggests that if the consumers are sensitive to the product's innovation level, the manufacturer should choose the IC to gain more profit for the whole supply chain; it also improves the competitiveness of the supply chain.

Figure 4(b) illustrates the trajectories of the product's level of innovation with respect to $\beta$. As a benchmark, the innovation level in the centralized scenario is very sensitive to $\beta$; we can see that $q^{C *}$ is a convex function with respect to $\beta$, which means that the acceleration of $q^{\mathrm{C} *}$ increases with $\beta$. $q^{\mathrm{C} *}$ becomes very high if $\beta$ tends to 1 . This is because the members make decisions as a whole and the decision variables are significantly high in this scenario. On the other hand, the IC is beneficial for the innovation of product because it is sensitive to the consumers' innovation need, as shown in the curve of $q^{\mathrm{DC} *}$ in Figure 4(b). The reason is that the reward offered by the manufacturer makes the retailer work harder to collect the consumers' knowledge, thereby improving the innovation level of product. Notice the curves of $q^{\mathrm{DW} *}$ and $q^{\mathrm{DT} *}$ in Figure $4(\mathrm{~b})$; one may find that they are very similar to each other as the $\beta$ varied. It implies that the effort target committed by the manufacturer in ICT cannot produce the corresponding level of innovation, with respect to the consumer's sensitivity of innovation.

The steady-state profit value of the supply chain with respect to $y_{0}$ and $\delta$ is shown in Figure 5(a). The ICT can affect the profit of supply chain via two factors: the target effort $y_{0}$ committed by the manufacturer and the marginal reward $\delta$. Figure 5(a) shows that $y_{0}$ has little impact on supply chain profit under ICT; it is equivalent to the fact which was shown in Figure 3(b). On the other hand, we consider the impact of $\delta$ on supply chain's profit. As $\delta$ increases, the profit increases first and then decreases. If $\delta$ is relatively small, the retailer does not have enough incentive to make efforts in collection of consumer's knowledge, and the manufacturer, as the upstream enterprise, has limited impact on the level of innovation. Hence, the profit is also relatively low. The profit of supply chain increases with $\delta$; it follows that the higher marginal reward improves the supply chain's profit when it is relatively low. Notice that there is a marginal reward $\delta^{*}$, such that the profit value function attains its maximum at $\delta^{*}$. If $\delta \in\left(\delta^{*}, 1\right)$, the profit decreases with $\delta$. As shown in Theorem 4, the retailer's optimal effort is independent of the effort target, and the manufacturer's incentive cost increases; hence, the incentive effect of $\delta$ to the profit of supply chain shows a decreasing trend.

Figure 5(b) illustrates the optimal profit value functions of the manufacturer and the retailer under ICT, respectively. The profit of the retailer is higher than the one of the manufacturer, since the retailer received an effort reward offered by the manufacturer. The retailer prefers a high marginal reward and a low effort target. Specifically, if $y_{0}$ is low, the retailer's profit increases with $\delta$, whereas the manufacturer's profit decreases with $\delta$. It is similar to the case under IC. If $y_{0}$ gets higher, the impacts of $\delta$ on retailer's profit become small. If $\delta$ is high, the effort target $y_{0}$ can lower the retailer's profit significantly. It implies that the retailer's profit suffers loss under the effort target committed by manufacturer. On the other hand, the manufacturer prefers the high effort target, whereas there exists a marginal reward $\delta^{*}$ such that the manufacturer can attain the maximum profit at any specific target $y_{0}>0$. The reason of existence 
and the expression of $\delta^{*}$ still remain unknown; we leave them as future study. Interestingly, if the effort target $y_{0}$ is high enough, it seems like manufacturer's and the retailer's profits have little connection with marginal reward $\delta$. The reason is that if the effort target committed by the manufacturer is high, the retailer has to make a lot of effort, and undertakes high cost in collection of consumer's knowledge. It leads to the fact that the retailer does not make much efforts in the collection of consumer's knowledge; hence, the innovation level of product cannot be improved efficiently. From the analysis of Figure 3(a), it follows that the profit of retailer is not be affected by the marginal reward.

\section{Conclusion}

The innovation level of product has been concerned by consumers, and consumer's preference for innovation plays a more active role in the market demand. Much attention has been paid to the research on the collaborative innovation of supply chain members and its long-term cooperative mechanism. Inspired by this phenomenon, we study a twoechelon supply chain composed of one manufacturer and one retailer in three transfer payment contract situations under dynamic settings, including the wholesale price contract, the incentive contract based on the effort in consumer's knowledge collection (IC), and the incentive contract based on the target effort in consumer's knowledge collection (ICT). The dynamic programming and the differential game theories are used to solve these dynamic problems. Considering that these contacts may lead to different results, the equilibrium $\mathrm{R} \& \mathrm{D}$ investment, the efforts in collection of consumer's knowledge, and the retail price of products are analyzed in the Stackelberg game. Finally, simulation and sensitivity analyses are carried out from the aspects of effort target, innovation sensitivity, and supply chain coordination. The major results of the paper include following aspects.

First, the manufacturer's optimal R\&D investment under the wholesale price contract is lower than the ones in the IC and ICT situations in decentralized scenarios, and the optimal investments are all constants, which means that they are independent from the time $t$. The manufacturer's R\&D investments do not change as the innovation level varies, which indicates that the $\mathrm{R} \& \mathrm{D}$ investment of manufacturers is stable and continuous in order to maintain the innovation level of products. In the wholesale price contract, the manufacturer has to invest more in the $R \& D$, since the retailer is less likely to make more effort in collection of consumer's knowledge without an incentive. However, in the IC and ICT situation, we found that the R\&D investments are identical. The reason is that the reward offered by the manufacturer does not affect the his decision in his own $\mathrm{R} \& \mathrm{D}$ investment. In the benchmark model, i.e., the centralized decision scenario, the manufacturer's optimal R\&D investment depends on the innovation level and R\&D investment increases with the product innovation level.

Second, the retailer's optimal efforts in the collection of consumer's knowledge are time-varied and tend to the steady states. The retailer is likely to make more effort (even higher than the effort in the centralized decision scenario) under the IC to gain the reward offered by the manufacturer. The steady state of optimal effort under this contract is very close to the one in the centralized scenario and even higher than the centralized scenario in the early time. We also conclude that the retailer's effort in collection of consumer's knowledge influences the innovation level of product significantly under IC. The retailer is less likely to make more effort in the wholesale price contract, since she has no incentive to do such things. We also found that the retailer's optimal effort is independent from the effort target set by the manufacturer in the dynamic model. Considering the intertemporal impact, the optimal decision of the retailer is to make more effort in collection of consumer's knowledge than the manufacturer's target, so as to obtain more profit.

Third, the retail price is significantly high under the IC; since the retailer makes more effort in this situation, she asks for higher price to cover the cost of efforts. The retail prices under the ICT and the wholesale price contract are very close. It shows that the effort target committed by the manufacturer does not improve the retail price of products. Interestingly, the retail price in the centralized decision case was initially lower than that in the decentralized decision case. However, over time, the retail price in the centralized decision scenario exceeded the prices under the wholesale price contract, and the price under the ICT subsequently, and finally, tended to the steady state of the optimal price under the IC.

Finally, to our surprise, the profits of supply chain under the ICT are very close to the one under the wholesale price contract. This counterintuitive result shows that the effort target committed by the manufacturer has little impact on the profit of the entire supply chain. To improve the overall profit of the supply chain, it is better to adopt the IC to coordinate the supply chain. Similarly, the IC is significantly better than the other two in terms of improving the innovation level of products. In the sensitivity analysis, the difference between profits of supply chain under ICT and the wholesale price contract tends to 0 , as the coefficient of the innovation level becomes large. It shows that when the consumers do not care or when they are extremely sensitive to the innovation level of product, there is no difference between ICT and the wholesale price contract. The ICT can be more beneficial to the supply chain only if the consumers' innovation sensitivity is medium. Therefore, our model suggests that if the consumers are sensitive to the product's innovation level, the manufacturer should choose the IC to gain more profit for the whole supply chain, and it also improves the competitiveness of the supply chain.

This study shows that the coordination mechanism of the supply chain in the dynamic case is quite different from that in the static case $[7,13]$. It shows that under the innovation-driven market demand, supply chain enterprises should adopt appropriate incentive contracts as a collaborative mechanism to improve the innovation level of products and thus obtain greater profits. To be specific, the manufacturer should offer the retailer a discount in the transfer payment rather than committing an effort target to her if he wants to improve product's innovation level. When 
the innovation level of products accumulates to a certain extent, the manufacturer can set an appropriate target for the retailer. This can not only ensure the continuous improvement of innovation level but also enable the supply chain members to obtain more profits.

This study has several limitations, and sufficient room is available to extend this research in the future. The marginal reward offered by the manufacturer has more implications than this study has shown; we shall investigate the optimal marginal reward offered in the transfer payment to maximize the profit of the supply chain. This study is mainly about the coordination of offline supply chain model; hence, it will be necessary to consider the collaborative innovation in a dual-channel supply chain. The level of innovation is deterministic in this study; however, there are uncertainties during the enterprise's innovation process. It could be interesting to extend the level of innovation to a stochastic case. In addition, we shall derive the optimal decisions by using the stochastic dynamic programming method.

\section{Appendix}

Proof of Proposition 1. According to optimal control theory, the optimal value function $V_{\mathrm{s}}^{\mathrm{C}}(q)$ of the integrated supply chain's profit at time $t$ is given by $V_{s}^{\mathrm{C}}(q)=e^{r t} J_{\mathrm{s}}^{\mathrm{C} *}$, which satisfies the Hamilton-Jacobi-Bellman equation as

$$
r V_{s}^{\mathrm{C}}(q)=\max _{p, x, y}\left[p(t) D(t)-\frac{1}{2} \lambda x^{2}-\frac{1}{2} \eta y^{2}+V_{s}^{\mathrm{C}^{\prime}}(q)(x+\gamma y-\tau q)\right] .
$$

The necessary conditions for the optimal strategies are given by

$$
\begin{aligned}
& p^{\mathrm{C} *}=\frac{(\alpha+\beta q)}{2}, \\
& x^{\mathrm{C} *}=\frac{V_{s}^{\mathrm{C}^{\prime}}}{\lambda}, \\
& y^{\mathrm{C} *}=\frac{\gamma V_{\mathrm{s}}^{\mathrm{C}^{\prime}}}{\eta} .
\end{aligned}
$$

Substituting the above equalities into (A.1) yields

$$
r V_{s}^{\mathrm{C}}(q)=\left[\frac{(\alpha+\beta q)^{2}}{4}+\frac{\left(\eta+\lambda \gamma^{2}\right)\left(V_{s}^{\mathrm{C}^{\prime}}\right)^{2}}{2 \lambda \eta}-\tau q V_{\mathrm{s}}^{\mathrm{C}^{\prime}}\right] \text {. }
$$

According to (A.2), we assume $V_{s}^{\mathrm{C}}(q)$ is a quadratic function with respect to $q$ :

$$
V_{s}^{C}(q)=f_{1} q^{2}+f_{2} q+f_{3},
$$

where $f_{1}, f_{2}$, and $f_{3}$ are unknown constants. Combining equations (A.3) and (A.4), we obtain

$$
\begin{aligned}
r & \left(f_{1} q^{2}+f_{2} q+f_{3}\right) \\
\quad & =\left[\frac{(\alpha+\beta q)^{2}}{4}+\frac{\left(\eta+\lambda \gamma^{2}\right)\left(2 f_{1} q+f_{2}\right)^{2}}{2 \lambda \eta}-\tau q\left(2 f_{1} q+f_{2}\right)\right] .
\end{aligned}
$$

Compare the left side of the equation above with its right side. We can solve $f_{1}, f_{2}$, and $f_{3}$ through a system of ternary linear equations as follows:

$$
\left\{\begin{array}{l}
r f_{1}=\frac{\beta^{2}}{4}+\frac{2\left(\eta+\lambda \gamma^{2}\right) f_{1}^{2}}{\lambda \eta}-2 \tau f_{1} \\
r f_{2}=\frac{\beta \alpha}{2}+\frac{2\left(\eta+\lambda \gamma^{2}\right) f_{1} f_{2}}{\lambda \eta}-\tau f_{2} \\
r f_{3}=\frac{\alpha^{2}}{4}+\frac{\left(\eta+\lambda \gamma^{2}\right) f_{2}^{2}}{2 \lambda \eta}
\end{array}\right.
$$

There are two roots for $f_{1}$ during the calculation. By further calculation, the larger root would imply that the dynamics of production quality do not converge to a steady state value, so only the smaller root is considered in the following:

$$
\begin{aligned}
& f_{1}=\frac{\lambda \eta(r+2 \tau)-\sqrt{\lambda^{2} \eta^{2}(r+2 \tau)^{2}-2 \lambda \eta \beta^{2}\left(\eta+\lambda \gamma^{2}\right)}}{4\left(\eta+\lambda \gamma^{2}\right)}, \\
& f_{2}=\frac{\beta \lambda \eta \alpha}{\lambda \eta r+\sqrt{\lambda^{2} \eta^{2}(r+2 \tau)^{2}-2 \lambda \eta \beta^{2}\left(\eta+\lambda \gamma^{2}\right)}}, \\
& f_{3}=\frac{\left(\eta+\lambda \gamma^{2}\right) f_{2}^{2}}{2 r \lambda \eta}+\frac{\alpha^{2}}{4 r} .
\end{aligned}
$$

Insert $f_{1}$ and $f_{2}$ into the forms of $V_{\mathrm{s}}^{\mathrm{C}^{\prime}}$ as follows and then substitute the expressions of $V_{s}^{C^{\prime}}$ into the optimal R\&D investment, consumer knowledge investment, and retail price and combine the similar terms.

$$
\begin{aligned}
V_{\mathrm{s}}^{\mathrm{C}}= & \frac{\lambda \eta(r+2 \tau)-\sqrt{\lambda^{2} \eta^{2}(r+2 \tau)^{2}-2 \lambda \eta \beta^{2}(\eta+\lambda}}{2\left(\eta+\lambda \gamma^{2}\right)} \\
& +\frac{\beta \lambda \eta \alpha}{\lambda \eta r+\sqrt{\lambda^{2} \eta^{2}(r+2 \tau)^{2}-2 \lambda \eta \beta^{2}\left(\eta+\lambda \gamma^{2}\right)}}
\end{aligned}
$$

Proof of Proposition 2. According to the optimal control theory, the optimal value function of the manufacturer and retailer's profit at time $t$ is given by

$$
\begin{array}{r}
J_{\mathrm{m}}^{\mathrm{DW} *}(x)=e^{-r t} V_{\mathrm{m}}^{\mathrm{DW}}(q), \\
J_{\mathrm{r}}^{\mathrm{DW} *}(y, p)=e^{-r t} V_{\mathrm{r}}^{\mathrm{DW}}(q) .
\end{array}
$$


$V_{\mathrm{m}}^{\mathrm{DW}}(q)$ and $V_{\mathrm{r}}^{\mathrm{DW}}(q)$ satisfy the Hamilton-Jacobi-Bellman function as

$$
\begin{aligned}
r V_{\mathrm{m}}^{\mathrm{DW}}(q)= & \max _{x}\left[w(\alpha-p+\beta q)-\frac{\lambda}{2} x^{2}\right. \\
& \left.+V_{\mathrm{m}}^{\mathrm{DW}^{\prime}}(x(t)+\gamma y(t)-\tau q)\right], \\
r V_{\mathrm{r}}^{\mathrm{DW}}(q)= & \max _{y, p}\left[(p-w)(\alpha-p+\beta q)-\frac{\eta}{2} y^{2}\right. \\
& \left.+V_{\mathrm{r}}^{\mathrm{DW}^{\prime}}(x(t)+\gamma y(t)-\tau q)\right] .
\end{aligned}
$$

The necessary conditions for the optimal strategies of (A.10) and (A.11) are given by the first-order conditions, which, respectively, imply

$$
\begin{aligned}
& y^{\mathrm{DW} *}=\frac{\gamma V_{r}^{\mathrm{DW}^{\prime}}}{\eta}, \\
& p^{\mathrm{DW} *}=\frac{\alpha+\beta q+w}{2}, \\
& x^{\mathrm{DW} *}=\frac{V_{\mathrm{m}}^{\mathrm{DW}^{\prime}}}{\lambda} .
\end{aligned}
$$

By substituting (A.12) into (A.10) and (A.11), we obtain

$$
\begin{aligned}
& r V_{\mathrm{m}}^{\mathrm{DW}}(q)=\frac{w(\alpha+\beta q-w)}{2}+\frac{\left(V_{\mathrm{m}}^{\mathrm{DW}^{\prime}}\right)^{2}}{2 \lambda}+\frac{\gamma^{2} V_{\mathrm{m}}^{\mathrm{DW}^{\prime}} V_{\mathrm{r}}^{\mathrm{DW}^{\prime}}}{\eta}-\tau q V_{\mathrm{m}}^{\mathrm{DW}^{\prime}}, \\
& r V_{\mathrm{r}}^{\mathrm{DW}}(q)=\frac{(\alpha+\beta q-w)^{2}}{4}+\frac{\gamma^{2}\left(V_{\mathrm{r}}^{\mathrm{DW}^{\prime}}\right)^{2}}{2 \eta}+\frac{V_{\mathrm{m}}^{\mathrm{DW}^{\prime}} V_{\mathrm{r}}^{\mathrm{DW}^{\prime}}}{\lambda}-\tau q V_{\mathrm{r}}^{\mathrm{DW}^{\prime}} .
\end{aligned}
$$

According to (A.13), we assume $V_{\mathrm{m}}^{\mathrm{DW}}(q)$ and $V_{\mathrm{r}}^{\mathrm{DW}}(q)$ are linear function and quadratic function of $q$, respectively.

$$
\left\{\begin{array}{l}
V_{\mathrm{m}}^{\mathrm{DW}}(q)=m_{1} q+m_{2}, \\
V_{\mathrm{r}}^{\mathrm{DW}}(q)=h_{1} q^{2}+h_{2} q+h_{3},
\end{array}\right.
$$

where $m_{1}, m_{2}, h_{1}, h_{2}$, and $h_{3}$ are unknown constants.

By substituting (A.14) into (A.15), we obtain

$$
\left\{\begin{array}{l}
(r+\tau) m_{1}-\frac{2 \gamma^{2} h_{1} m_{1}}{\eta}-\frac{\beta w}{2}=0, \\
\frac{w(\alpha-w)}{2}+\frac{m_{1}^{2}}{2 \lambda}+\frac{\gamma^{2} m_{1} h_{2}}{\eta}-r m_{2}=0, \\
\frac{\beta^{2}}{4}+\frac{2 \gamma^{2} h_{1}^{2}}{\eta}-(r+2 \tau) h_{1}=0, \\
\frac{\beta(\alpha-w)}{2}+\frac{2 h_{1} h_{2} \gamma^{2}}{\eta}+\frac{2 m_{1} h_{1}}{\lambda}-(r+\tau) h_{2}=0, \\
\frac{(\alpha-w)^{2}}{4}+\frac{\gamma^{2} h_{2}^{2}}{2 \eta}+\frac{m_{1} h_{2}}{\lambda}-r h_{3}=0,
\end{array}\right.
$$

which implies that

$$
\begin{aligned}
& h_{1}=\frac{\eta(r+2 \tau)-\sqrt{\eta^{2}(r+2 \tau)^{2}-2 \gamma^{2} \eta \beta^{2}}}{4 \gamma^{2}}, \\
& m_{1}=\frac{\beta \eta w}{\eta r+\sqrt{\eta^{2}(r+2 \tau)^{2}-2 \gamma^{2} \eta \beta^{2}}}, \\
& h_{2}=\frac{\eta \lambda \beta(\alpha-w)+\left(\left(\beta \eta^{2} w\left(\eta(r+2 \tau)-\sqrt{\eta^{2}(r+2 \tau)^{2}-2 \gamma^{2} \eta \beta^{2}}\right)\right) /\left(\gamma^{2}\left(\eta r+\sqrt{\eta^{2}(r+2 \tau)^{2}-2 \gamma^{2} \eta \beta^{2}}\right)\right)\right)}{\eta \lambda r+\lambda \sqrt{\eta^{2}(r+2 \tau)^{2}-2 \gamma^{2} \eta \beta^{2}}} .
\end{aligned}
$$

Substitute $m_{1}, h_{1}$, and $h_{2}$ into the derivative functions of (A.14) and plug the expressions of $V_{\mathrm{m}}^{\mathrm{DW}^{\prime}} V_{\mathrm{r}}^{\mathrm{DW}^{\prime}}$ into (A.12). Thus, the optimal R\&D investment, consumer knowledge investment, and retail price in the decentralized scenario with wholesale price contract can be obtained.
Proof of Proposition 3. The proof of Proposition 3 is similar to that of Proposition 2; hence, we only present the key solution procedures here. Differentiating the HJB equations with respect to $y, x$, and $p$, the optimal decisions can be expressed as 


$$
\begin{gathered}
y^{\mathrm{DC} *}=\frac{\delta+\gamma V_{\mathrm{r}}^{\mathrm{DC}^{\prime}}}{\eta}, \\
p^{\mathrm{DC} *}=\frac{\alpha+\beta q+w}{2}, \\
x^{\mathrm{DC} *}=\frac{V_{\mathrm{m}}^{\mathrm{DW}^{\prime}}}{\lambda} .
\end{gathered}
$$

By substituting (A.17) and (A.18) into the HJB equations, we obtain

$$
\begin{aligned}
r V_{\mathrm{m}}^{\mathrm{DC}}(q)= & \frac{w(\alpha+\beta q-w)}{2}+\frac{\left(V_{\mathrm{m}}^{\mathrm{DC}^{\prime}}\right)^{2}}{2 \lambda}+\frac{\left(\gamma V_{\mathrm{r}}^{\mathrm{DC}^{\prime}}+\delta\right)\left(\gamma V_{\mathrm{m}}^{\mathrm{DC}^{\prime}}-\delta\right)}{\eta} \\
& -\tau q V_{\mathrm{m}}^{\mathrm{DC}^{\prime}}, \\
r V_{\mathrm{r}}^{\mathrm{DC}}(q)= & \frac{(\alpha+\beta q-w)^{2}}{4}+\frac{\left(\delta+\gamma V_{\mathrm{r}}^{\mathrm{DC}^{\prime}}\right)^{2}}{2 \eta}+\frac{V_{\mathrm{m}}^{\mathrm{DC}^{\prime}} V_{\mathrm{r}}^{\mathrm{DC}^{\prime}}}{\lambda}-\tau q V_{\mathrm{r}}^{\mathrm{DC}^{\prime}} .
\end{aligned}
$$

Substituting the general function forms $V_{\mathrm{m}}^{\mathrm{DC}}(q)=g_{1} q+g_{2}, \quad V_{\mathrm{r}}^{\mathrm{DC}}(q)=j_{1} q^{2}+j_{2} q+j_{3} \quad$ into the equations above and comparing the left sides of the equations with their right sides, we obtain

$$
\left\{\begin{array}{l}
2 \eta(r+\tau) g_{1}-\eta w \beta-4 \gamma j_{1}\left(\gamma g_{1}-\delta\right)=0 \\
\lambda \eta w(\alpha-w)+\eta g_{1}^{2}+2 \lambda\left(\gamma j_{2}+\delta\right)\left(\gamma g_{1}-\delta\right) \\
-2 \lambda \eta r g_{2}=0 \\
8 \gamma^{2} j_{1}^{2}-(8 \eta \tau+4 \eta r) j_{1}+\eta \beta^{2}=0 \\
\eta \lambda \beta(\alpha-w)+4 \lambda \gamma j_{1}\left(\delta+\gamma j_{2}\right)+4 \eta g_{1} j_{1} \\
-2(r+\tau) \eta \lambda j_{2}=0 \\
\eta \lambda(\alpha-w)^{2}+2 \lambda\left(\delta+\gamma j_{2}\right)^{2}+4 \eta g_{1} j_{2}-4 \eta \lambda r j_{3}=0
\end{array}\right.
$$

which implies that

$$
\begin{aligned}
j_{1}= & \frac{\eta(r+2 \tau)-\sqrt{\eta^{2}(r+2 \tau)^{2}-2 \gamma^{2} \eta \beta^{2}}}{4 \gamma^{2}}, \\
g_{1}= & \frac{\gamma \eta w \beta-\delta \eta(2 \tau+r)+\delta \sqrt{\eta^{2}(r+2 \tau)^{2}-2 \gamma^{2} \eta \beta^{2}}}{\gamma \eta r+\gamma \sqrt{\eta^{2}(r+2 \tau)^{2}-2 \gamma^{2} \eta \beta^{2}}}, \\
j_{2}= & \frac{\eta \lambda \beta(\alpha-w)+4 \eta j_{1} g_{1}}{\eta \lambda r+\lambda \sqrt{\eta^{2}(r+2 \tau)^{2}-2 \gamma^{2} \eta \beta^{2}}} \\
& +\frac{\lambda \delta\left(\left(\eta(r+2 \tau)-\sqrt{\eta^{2}(r+2 \tau)^{2}-2 \gamma^{2} \eta \beta^{2}}\right) / \gamma\right)}{\eta \lambda r+\lambda \sqrt{\eta^{2}(r+2 \tau)^{2}-2 \gamma^{2} \eta \beta^{2}}} .
\end{aligned}
$$

Substitute $g_{1}, j_{1}$, and $j_{2}$ into the functions $V_{\mathrm{m}}^{\mathrm{DC}}(q)=$ $g_{1} q+g_{2}, V_{\mathrm{r}}^{\mathrm{DC}}(q)=j_{1} q^{2}+j_{2} q+j_{3}$ and plug the expressions of $V_{\mathrm{m}}^{\mathrm{DC}^{\prime}}, V_{\mathrm{r}}^{\mathrm{DC}^{\prime}}$ into (A.17) and (A.18). Thus, the optimal R\&D investment, consumer knowledge investment, and retail price in the decentralized scenario with consumer knowledge investment contract can be obtained.

Proof of Proposition 4. According to the optimal control theory, the optimal value function of the manufacturer's profit $V_{\mathrm{m}}^{\mathrm{DT}}(q)$ and retailer's profit $V_{\mathrm{r}}^{\mathrm{DT}}(q)$ at time $t$ is given by

$$
\begin{aligned}
& V_{\mathrm{m}}^{\mathrm{DT}}(q)=e^{r t} J_{\mathrm{m}}^{\mathrm{DT} *}(x), \\
& V_{\mathrm{r}}^{\mathrm{DT}}(q)=e^{r t} J_{\mathrm{r}}^{\mathrm{DT} *}(y, p),
\end{aligned}
$$

respectively. $V_{\mathrm{m}}^{\mathrm{DT}}(q)$ and $V_{\mathrm{r}}^{\mathrm{DT}}(q)$ satisfy the Hamilton-Jacobi-Bellman equation as

$$
\begin{aligned}
r V_{\mathrm{m}}^{\mathrm{DT}}(q)= & \max _{x}\left[w(\alpha-p+\beta q)-\delta\left(y-y_{0}\right)^{+}-\frac{\lambda}{2} x^{2}\right. \\
& \left.+V_{\mathrm{m}}^{\mathrm{DT}^{\prime}}(x(t)+\gamma y(t)-\tau q)\right],
\end{aligned}
$$

$$
\begin{aligned}
r V_{\mathrm{r}}^{\mathrm{DT}}(q)= & \max _{y, p}\left[(p-w)(\alpha-p+\beta q)+\delta\left(y-y_{0}\right)^{+}-\frac{\eta}{2} y^{2}\right. \\
& \left.+V_{\mathrm{r}}^{\mathrm{DT}^{\prime}}(x(t)+\gamma y(t)-\tau q)\right] .
\end{aligned}
$$

If $y<y_{0}$, then the model degrades into the case of the wholesale price contract (Section 2); hence, we consider only the case $y>y_{0}$. Differentiating (A.23) and (A.24) with respect to $y, x$, and $p$, we obtain the optimal decisions as follows:

$$
\begin{aligned}
& y^{\mathrm{DT} *}=\frac{\delta+\gamma V_{\mathrm{r}}^{\mathrm{DT}}}{\eta}, \\
& p^{\mathrm{DT} *}=\frac{\alpha+\beta q+w}{2}, \\
& x^{\mathrm{DT} *}=\frac{V_{\mathrm{m}}^{\mathrm{DT}^{\prime}}}{\lambda} .
\end{aligned}
$$

By substituting (A.25) and (A.26) into (A.23) and (A.24), we obtain

$$
\begin{aligned}
r V_{\mathrm{m}}^{\mathrm{DT}}= & \frac{w \beta}{2} q+\frac{w(\alpha-w)}{2}-\frac{\delta^{2}}{\eta}+\delta y_{0}-\frac{\delta \gamma}{\eta} V_{\mathrm{r}}^{\mathrm{DT}^{\prime}}+\frac{\left(V_{\mathrm{m}}^{\mathrm{DT}^{\prime}}\right)^{2}}{2 \lambda} \\
& +\frac{\gamma \delta}{\eta} V_{\mathrm{m}}^{\mathrm{DT}^{\prime}}+\frac{\gamma^{2}}{\eta} V_{\mathrm{m}}^{\mathrm{DT}^{\prime}} V_{\mathrm{r}}^{\mathrm{DT}^{\prime}}-\tau q V_{\mathrm{m}}^{\mathrm{DT}^{\prime}}, \\
r V_{\mathrm{r}}^{\mathrm{DT}}= & \frac{\beta^{2}}{4} q^{2}+\frac{(\alpha-w) \beta}{2} q+\frac{(\alpha-w)^{2}}{4}+\frac{\delta^{2}}{2 \eta}-\delta y_{0}+\frac{\gamma \delta V_{\mathrm{r}}^{\mathrm{DT}^{\prime}}}{\eta} \\
& +\frac{\gamma^{2}\left(V_{\mathrm{r}}^{\mathrm{DT}^{\prime}}\right)^{2}}{2 \eta}+\frac{V_{\mathrm{r}}^{\mathrm{DT}^{\prime}} V_{\mathrm{m}}^{\mathrm{DT}^{\prime}}}{\lambda}-\tau q\left(V_{\mathrm{r}}^{\mathrm{DT}^{\prime}}\right) .
\end{aligned}
$$


According to (A.27) and (A.28), we assume $V_{\mathrm{m}}^{\mathrm{DT}}(q)$ and $V_{\mathrm{r}}^{\mathrm{DT}}(q)$ are linear and quadratic functions of $q$, respectively.

$$
\left\{\begin{array}{l}
V_{\mathrm{m}}^{\mathrm{DT}}(q)=k_{1} q+k_{2}, \\
V_{\mathrm{r}}^{\mathrm{DT}}(q)=l_{1} q^{2}+l_{2} q+l_{3},
\end{array}\right.
$$

where $k_{1}, k_{2}, l_{1}, l_{2}$, and $l_{3}$ are unknown constants.

By substituting (A.29) into (A.27) and (A.28), we obtain

$$
\left\{\begin{array}{l}
2 \eta(r+\tau) k_{1}-\eta w \beta+4 \delta \gamma l_{1}-4 \gamma^{2} k_{1} l_{1}=0, \\
\eta \lambda w(\alpha-w)-2 \lambda \delta^{2}+2 \eta \lambda \delta y_{0}-2 \lambda \delta \gamma l_{2}+\eta k_{1}^{2} \\
+2 \lambda \gamma \delta k_{1}+2 \lambda \gamma^{2} k_{1} l_{2}-2 \eta \lambda r k_{2}=0, \\
8 \gamma^{2} l_{1}^{2}-(8 \eta \tau+4 \eta r) l_{1}+\eta \beta^{2}=0, \\
\eta \lambda \beta(\alpha-w)+4 \lambda \gamma \delta l_{1}+4 \lambda \gamma^{2} l_{1} l_{2}+4 \eta l_{1} k_{1} \\
-2 \eta \lambda(\tau+r) l_{2}=0, \\
\eta \lambda(\alpha-w)^{2}+2 \lambda \delta^{2}-4 \eta \lambda \delta y_{0}+4 \lambda \gamma \delta l_{2}+2 \lambda \gamma^{2} l_{2}^{2} \\
+4 \eta l_{2} k_{1}-4 \eta \lambda r l_{3}=0,
\end{array}\right.
$$

which implies that

$$
\begin{aligned}
& l_{1}=\frac{\eta\left(2 \tau+r-\sqrt{\left((2 \tau+r)^{2}-2 \gamma^{2} \beta^{2} / \eta\right)}\right)}{4 \gamma^{2}}, \\
& k_{1}=\frac{\gamma w \beta-\delta\left((2 \tau+r)-\sqrt{\left((2 \tau+r)^{2}-2 \gamma^{2} \beta^{2} / \eta\right)}\right)}{\gamma\left(r+\sqrt{\left((2 \tau+r)^{2}-2 \gamma^{2} \beta^{2} / \eta\right)}\right)} \\
& l_{2}=\frac{4 \lambda \gamma \delta l_{1}+4 \eta l_{1} k_{1}+\eta \lambda \beta(\alpha-w)}{\lambda \eta\left(\sqrt{\left((2 \tau+r)^{2}-2 \gamma^{2} \beta^{2} / \eta\right)}+r\right)} .
\end{aligned}
$$

Substitute $k_{1}, l_{1}$, and $l_{2}$ into the derivative functions of (A.29) and plug the expressions of $V_{\mathrm{m}}^{\mathrm{DT}^{\prime}}, V_{\mathrm{r}}^{\mathrm{DT}^{\prime}}$ into (A.25) and (A.26). Thus, the optimal R\&D investment, consumer knowledge investment, and retail price in the decentralized scenario with target of consumer knowledge effort contract can be obtained.

\section{Data Availability}

No data were used to support this study.

\section{Conflicts of Interest}

The authors declare that there are no conflicts of interest regarding the publication of this paper.

\section{Acknowledgments}

This research was supported by the Humanity and Social Science Youth Foundation of Ministry of Education of China (no. 19YJC630051) and the National Social Science Foundation of China (nos. 18BGL147 and 18CGL003).

\section{References}

[1] Y.-Z. Chen and W. Chen, "Incentive contracts of knowledge investment for cooperative innovation in project-based supply chain with double moral hazard," Soft Computing, vol. 24, no. 4, pp. 2693-2702, 2020.

[2] F. Lu, J. Zhang, and W. Tang, "Wholesale price contract versus consignment contract in a supply chain considering dynamic advertising," International Transactions in Operational Research, vol. 26, no. 5, pp. 1977-2003, 2019.

[3] S. B. Wu, X. Gu, G. D. Wu, and Q. Zhou, "Cooperative R\&D contract of supply chain considering the quality of product innovation," International Journal of Simulation Modelling, vol. 15, no. 2, pp. 341-351, 2016.

[4] L. Lambertini and R. Orsini, "Quality improvement and process innovation in monopoly: a dynamic analysis," Operations Research Letters, vol. 43, no. 4, pp. 370-373, 2015.

[5] Z. Ge, Q. Hu, and Y. Xia, "Firms' R\&D cooperation behavior in a supply chain," Production and Operations Management, vol. 23, no. 4, pp. 599-609, 2014.

[6] K.-K. Kim and M. K. Lim, "R\&D outsourcing in an innovation-driven supply chain," Operations Research Letters, vol. 43, no. 1, pp. 20-25, 2015.

[7] S. H. Yoo and T. Cheong, "Quality improvement incentive strategies in a supply chain," Transportation Research Part E: Logistics and Transportation Review, vol. 114, no. 6, pp. 331342, 2018.

[8] L. Lambertini, "Coordinating research and development efforts for quality improvement along a supply chain," European Journal of Operational Research, vol. 270, no. 2, pp. 599-605, 2018.

[9] X. Li, J. Chen, and X. Ai, "Contract design in a cross-sales supply chain with demand information asymmetry," European Journal of Operational Research, vol. 275, no. 3, pp. 939-956, 2019.

[10] H. Peng, T. Pang, and J. Cong, "Coordination contracts for a supply chain with yield uncertainty and low-carbon preference," Journal of Cleaner Production, vol. 205, no. 23, pp. 291-302, 2018.

[11] Z. Hong and X. Guo, "Green product supply chain contracts considering environmental responsibilities," Omega, vol. 83, no. 2, pp. 155-166, 2019.

[12] L. Xu, C. Wang, and J. Zhao, "Decision and coordination in the dual-channel supply chain considering cap-and-trade regulation," Journal of Cleaner Production, vol. 197, pp. 551$561,2018$.

[13] S. F. Alamdar, M. Rabbani, and J. Heydari, "Pricing, collection, and effort decisions with coordination contracts in a fuzzy, three-level closed-loop supply chain," Expert Systems with Applications, vol. 104, no. 4, pp. 261-276, 2018.

[14] Z. Song and S. He, "Contract coordination of new fresh produce three-layer supply chain," Industrial Management \& Data Systems, vol. 119, no. 1, pp. 148-169, 2019.

[15] M. Sun, H. Peng, and S. Wang, "Cost-sharing mechanisms for a wood forest product supply chain under carbon cap-andtrade," Sustainability, vol. 10, no. 12, pp. 4345-10, 2018.

[16] H. Zou, J. Qin, P. Yang, and B. Dai, "A coordinated revenuesharing model for a sustainable closed-loop supply chain," Sustainability, vol. 10, p. 9, 2018.

[17] D. Zhao, X. M. Zhang, T. H. Ren, and H. Y. Fu, "Optimal pricing strategies in a product and service supply chain with extended warranty service competition considering retailer fairness concern," Mathematical Problems in Engineering, vol. 2019, Article ID 8657463, 15 pages, 2019.

[18] J. H. Zhou, S. K. Li, and B. Wang, "Investigation of dynamic incentive of supply chain under information asymmetry for screening," Mathematical Problems in Engineering, vol. 2019, Article ID 9547931, 10 pages, 2019. 
[19] M. Noori-Daryan, A. A. Taleizadeh, and K. Govindan, "Joint replenishment and pricing decisions with different freight modes considerations for a supply chain under a composite incentive contract," Journal of the Operational Research Society, vol. 69, no. 6, pp. 876-894, 2018.

[20] A. A. Taleizadeh, N. Rabiei, and M. Noori-Daryan, "Coordination of a two-echelon supply chain in presence of market segmentation, credit payment, and quantity discount policies," International Transactions in Operational Research, vol. 26, no. 4, pp. 1576-1605, 2018.

[21] R. Dai, J. Zhang, and W. Tang, "Cartelization or cost-sharing? Comparison of cooperation modes in a green supply chain," Journal of Cleaner Production, vol. 156, no. 13, pp. 159-173, 2017.

[22] B. Davis-Sramek, R. Germain, and K. Krotov, "Examining the process R\&D investment-performance chain in supply chain operations: the effect of centralization," International Journal of Production Economics, vol. 167, no. 5, pp. 246-256, 2015.

[23] C.-H. Wu and Y.-J. Kao, "Cooperation regarding technology development in a closed-loop supply chain," European Journal of Operational Research, vol. 267, no. 2, pp. 523-539, 2018.

[24] V.-H. Lee, K.-B. Ooi, A. Y.-L. Chong, and A. Sohal, "The effects of supply chain management on technological innovation: the mediating role of Guanxi," International Journal of Production Economics, vol. 205, no. 1, pp. 15-29, 2018.

[25] M. Noori-Daryan, A. A. Taleizadeh, and F. Jolai, “Analyzing pricing, promised delivery lead time, supplier-selection, and ordering decisions of a multi-national supply chain under uncertain environment," International Journal of Production Economics, vol. 209, no. 3, pp. 236-248, 2019.

[26] A. A. Taleizadeh, M. Noori-Daryan, and K. Govindan, "Pricing and ordering decisions of two competing supply chains with different composite policies: a Stackelberg gametheoretic approach," International Journal of Production Research, vol. 54, no. 9, pp. 2807-2836, 2016.

[27] A. A. Taleizadeh, M. Noori-Daryan, and S. Sana, "Manufacturing and selling tactics for a green supply chain under a green cost sharing and a refund agreement," Journal of Modelling in Management, 2020.

[28] Y. Zu, L. Chen, and Y. Fan, "Research on low-carbon strategies in supply chain with environmental regulations based on differential game," Journal of Cleaner Production, vol. 177, no. 6, pp. 527-546, 2018.

[29] Y. Zhou and X. Ye, "Differential game model of joint emission reduction strategies and contract design in a dual-channel supply chain," Journal of Cleaner Production, vol. 190, no. 14, pp. 592-607, 2018.

[30] F. Liu, W.-L. Chen, and D.-B. Fang, "Optimal coordination strategy of dynamic supply chain based on cooperative stochastic differential game model under uncertain conditions," Applied Soft Computing, vol. 56, no. 1, pp. 669-683, 2017.

[31] Y. Yang and X. Xu, "A differential game model for closed-loop supply chain participants under carbon emission permits," Computers \& Industrial Engineering, vol. 135, no. 5, pp. 1077-1090, 2019.

[32] J. Zeng and B. Z. Li, "Research on cooperation strategy between government and green supply chain based on differential game," Open Mathematics, vol. 17, pp. 825-855, 2019.

[33] J. Xiao and Z. Huang, "A stochastic differential game in the closed-loop supply chain with third-party collecting and fairness concerns," Sustainability, vol. 11, no. 8, p. 2241, 2019.

[34] Z. Basiri and J. Heydari, "A mathematical model for green supply chain coordination with substitutable products,"
Journal of Cleaner Production, vol. 145, no. 5, pp. 232-249, 2017.

[35] P. Ma, H. Wang, and J. Shang, "Contract design for two-stage supply chain coordination: integrating manufacturer-quality and retailer-marketing efforts," International Journal of Production Economics, vol. 146, no. 2, pp. 745-755, 2013.

[36] G. Zhong and W. Zhang, "Product and process innovation with knowledge accumulation in monopoly: a dynamic analysis," Economics Letters, vol. 163, no. 2, pp. 175-178, 2018. 